\title{
Twenty-First Century Drought Analysis Across China using CMIP6 Under Climate Change
}

\section{Gengxi Zhang}

Northwest A \& F University

Thian Yew Gan ( $\nabla$ tgan@ualberta.ca )

University of Alberta https://orcid.org/0000-0002-5196-2846

\section{Xiaoling Su}

Northwest A \& F University

\section{Research Article}

Keywords: CMIP6, Drought analysis, Precipitation, Soil moisture, Runoff, scPDSI

Posted Date: November 15th, 2021

DOl: https://doi.org/10.21203/rs.3.rs-206879/v1

License: (1) This work is licensed under a Creative Commons Attribution 4.0 International License. Read Full License 


\section{Twenty-first century drought analysis across China}

\section{under climate change}

$4 \quad{ }^{1}$ College of Water Resources and Architectural Engineering, Northwest A \& F University, Yangling 5712100, China;

$6{ }^{2}$ Department of Civil and Environmental Engineering, University of Alberta, Edmonton, AB, 7 Canada;

$8 \quad{ }^{3}$ Key Laboratory for Agricultural Soil and Water Engineering in Arid Area of Ministry of Education,

9 Northwest A \& F University, Yangling 712100, China;

$10 *$ Correspondence: tgan@ualberta.ca (T.Y. Gan)

11 ORCID: Gengxi Zhang (0000-0002-8218-8910); Thian Yew Gan (0000-0002-5196-2846);

12 Xiaoling Su (0000-0002-8060-6701) 


\section{Abstract}

Under global warming, according to results obtained from offline drought indices driven by projections of general circulation models (GCMs), future droughts in China will worsen but the results are not consistent. We analyzed changes in droughts covering the entire hydrologic cycle using outputs of GCMs of the 6th Coupled Model Intercomparison Project (CMIP6) for SSP2-4.5 and SSP5-8.5 climate scenarios, and compared the results with that of popular, offline drought indices (the self-calibrating Palmer Drought Severity Index (scPDSI), Standardized Precipitation Evapotranspiration Index (SPEI) and Standardized Precipitation Actual Evapotranspiration Index (SPAEI)). Among meteorological, agricultural, and hydrological drought indices tested under both SSP scenarios, the results obtained from SPAEI and scPDSI agree better with univariate drought indices than SPEI. scPDSI generally agrees well with agricultural droughts (Standardized Soil Moisture Index with the surface soil moisture content; SSIS). Future droughts estimated using soil moisture analysis are more widespread than that from precipitation and runoff analysis in humid regions of South China by the end of the 21 st century. In arid northwestern China and Inner Mongolia, drought areas and severity based on scPDSI and SSIS forced with the SSP scenarios show obvious decreasing trends, in contrast to increasing trends projected in humid regions. Trends projected using SPEI contradict those projected by other drought indices in non-humid regions. Therefore, selecting appropriate drought indices are crucial in project representative future droughts and meaningful information needed to achieve effective regional drought mitigation strategies under climate warming impact.

Keywords: CMIP6 · Drought analysis · Precipitation · Soil moisture $\cdot$ Runoff $\cdot$ scPDSI

\section{Introduction}

Drought could occur nearly anywhere in the world especially in regions of the arid or semi-arid climate and could result in serious detrimental effects on agriculture, water supply, ecology, biodiversity, and economy (Zhang et al. 2021a, b). Recent climatic changes are rapid, intensifying, widespread and unprecedented, affecting every region on earth in many ways, making extreme climate events such as heavy precipitation and droughts to be more widespread, more frequent and 
in greater severity, particularly in 2021, which is causing long-term impacts on terrestrial, freshwater and marine ecosystems (Douville et al., 2021). Anthropogenic climate change due to ever-increasing greenhouse gas emissions has the potential to drastically alter climates over a wide range of spatial scales, leading to occurrences of more extreme climate (Scheepers et al. 2018). Under the influence of climate warming, the severity droughts will likely increase in many regions in recent decades (Yang et al. 2020a; Zhang et al. 2021a). For example, the 2011 summer drought in the mid- and lower- reaches of the Yangtze River basin in China had affected 30 million people and cost about 2.4 billion US dollars in damage (Yuan et al. 2015). The 2010 spring drought in southwestern China reduced the winter wheat production by $48 \%$ and $31 \%$ in Yunnan and Guizhou provinces, respectively (Zhang et al. 2012). Because severe droughts in China have caused severe economic losses, there are calls for China to implement strategic, adaptive measures to minimize the impacts of droughts, especially large-scale and/or prolonged droughts (Yao et al. 2020). Furthermore, projecting realistic changes to future droughts are also essential if we hope to make pragmatic decisions to achieve effective mitigation measures against the impact of droughts.

Droughts can be generally categorized into meteorological (deficit in precipitation), hydrological (deficiency in runoff), agricultural (low soil moisture), and socioeconomic (water supply cannot meet the water demand) droughts (American Meteorological Society 2013; Mehran et al. 2015; Mishra and Singh 2010; Liu et al. 2020). However, most droughts according to their physical characteristics can be categorized into the first three types (Wang et al. 2009). Drought indices are commonly used metrics to quantify and to compare different drought events. According to the World Meteorological Organization, more than 50 drought indices have been proposed to characterize droughts (Cheng et al. 2018). Among these, the Palmer Drought Severity Index (PDSI) (Palmer 1965), Self-Calibrating PDSI (scPDSI) (Wells et al. 2004), Standardized Precipitation Evapotranspiration Index (SPEI) (Vicente-Serrano et al. 2010b), Standardized Precipitation Index (SPI) (Mckee et al. 1993), Standardized Runoff Index (SRI) (Nalbantis and Tsakiris 2008), and Standardized Soil Moisture Index (SSI) (Hao and AghaKouchak 2013) are likely the most widely used indices. SPEI measures drought conditions based on the water balance, the differences between the atmospheric water supply (precipitation) and water demand (i.e., potential evapotranspiration, PET) (Zhang et al. 2019a, b). However, in water-limited regions (e.g., northwestern China), changes 
in the actual evapotranspiration are usually dominated by a change in precipitation rather than in PET (Ayantobo and Wei 2019; Yang et al. 2018a), which could hinder the applicability of SPEI in these regions. Instead of PET, actual evapotranspiration (AET) has been used to compute the Standardized Precipitation Actual Evapotranspiration Index (SPAEI) index, which has been found to show drought conditions more consistent with that of a hydrological drought index than SPEI (Joetzjer et al. 2013). Due to the better physical representation of PDSI, it has been a popular index to assess the severity of historical droughts (Chen et al. 2019) and to project future droughts from outputs of general circulation models (GCMs) (Gizaw and Gan 2016).

Outputs of GCMs are widely used for evaluating the effects of climate change on droughts, such as GCMs CMIP5 (the $5^{\text {th }}$ Coupled Model Intercomparison Project) (Taylor et al. 2012). Based on CMIP5 outputs, many studies indicated that climate warming could intensify droughts (aridity) because the projected increase in water demand (evaporation) generally exceeds the projected increase in water supply (precipitation) (Frierson and Scheff 2015; Gizaw and Gan 2016; Yao et al. 2020). Some studies indicated that projections based on drought indices such as SPEI may overestimate future changes in droughts partly due to neglecting the effects of increased $\mathrm{CO}_{2}$ on plant stomatal conductance, which may reduce the projected future increase in PET (Roderick et al. 2015; Yang et al. 2018a; Yang et al. 2020b). Besides, discrepancies between computation methods of offline PET models such as the Penman-Monteith and climate models may also result in overestimating future $P E T$ trends. Finally, computing metrics offline through combining climate model outputs with impact models (e.g., hydrological models) may introduce inconsistencies, which may cause an overestimation or underestimation of aridity and droughts (Berg et al. 2016; Swann et al. 2016). Therefore, some studies suggested that directly using actual changes in water cycle variables such as precipitation, runoff, and soil moisture simulated by climate models to project future droughts or aridity trends may be more representative than using offline drought indices.

Recent simulations by climate models participating in CMIP6 are now available (Eyring et al. 2016). Nine climate scenarios are available in CMIP6, among which the ScenarioMIP is developed from a scenario matrix architecture combining the Shared Socio-Economic Pathways (SSP) (O'Neill et al. 2013) with the representative concentration pathways (RCPs). This provides us with more robust and higher resolution simulations to analyze drought responses to climate change. 
Using multimodel ensemble (MME) simulations of ten GCMs from CMIP6 under SSP2-4.5 and SSP5-8.5 scenarios, we estimated precipitation, runoff, and soil moisture droughts of China, which represent the traditional meteorological, hydrological, and agricultural droughts, respectively. We further compare these three types of droughts with offline drought indices (scPDSI, SPEI and SPAEI) to investigate the applicability of offline drought indices in different climatic regions across China.

\section{Data sets}

\subsection{Study area}

China has a wide range of climatic regimes distributed from south to north, such as tropical monsoon, subtropical monsoon, temperate monsoon, temperate continental, and alpine plateau climate. Based on its long-term climatic conditions and topography, China can be divided into 7 geographical regions (Zhang et al. 2021a), which are temperate and warm-temperate northwestern China desert (Region 1), temperate grassland of Inner Mongolia (Region 2), Qinghai-Tibetan Plateau (Region 3), Temperate humid and sub-humid northeastern China (Region 4), Warm-temperate humid and subhumid northern China (Region 5), subtropical humid central and southern China (Region 6), tropical humid southern China (Region 7) (Fig. 1). The long-term mean climatic conditions of these regions are listed in Table 1.

\subsection{CMIP6 model outputs}

Historical and future climate change scenarios across China simulated by ten CMIP6 GCMs from North America, Europe, and Asia are listed in Table 2. Projected temperatures for future periods for SSP scenarios are SSP1-2.6 (+ 2.6 $\mathrm{W} \mathrm{m}^{-2}$; low forcing sustainability pathway), SSP2-4.5 (+ $4.5 \mathrm{~W}$ $\mathrm{m}^{-2}$; medium forcing middle-of-the-road pathway), SSP3-7.0 $\left(+7.0 \mathrm{~W} \mathrm{~m}^{-2}\right.$; medium- to high-end forcing pathway), and SSP5-8.5 (+ $8.5 \mathrm{~W} \mathrm{~m}^{-2}$; high-end forcing pathway). For the analysis of future droughts of China, among the SSP scenarios available, SSP2-4.5 and SSP5-8.5 scenarios were selected because they are the most used scenarios that project the global temperature to increase between $1.5^{\circ} \mathrm{C}$ and $2.0^{\circ} \mathrm{C}$ by the late 21 st century. These projected climate variables of CMIP6 are 


\subsection{Univariate drought indices, SPI, SSI, and SRI}

To comprehensively assess future droughts across China, three popular univariable drought indices, SPI, SSI, and SRI were estimated using ten GCMs' outputs: precipitation ( $\mathrm{pr}, \mathrm{mm} \mathrm{day}^{-1}$ ), the surface soil moisture content in the top $10 \mathrm{~cm}\left(\mathrm{mrsos}, \mathrm{kg} \mathrm{m}^{-2}\right)$, total soil moisture content ( $\left.\mathrm{mrso}, \mathrm{kg} \mathrm{m}^{-2}\right)$, total surface runoff leaving the land portion, excluding base flow drainage from the soil model (mrros, $\mathrm{mm} \mathrm{day}^{-1}$ ) and total runoff leaving the land portion, including drainage through the base of the soil moisture $\left(\mathrm{mrro}, \mathrm{mm} \mathrm{day}^{-1}\right)$. These selected variables essentially represent the three types of traditional droughts - meteorological, hydrological, and agricultural droughts. For clarity, SSI and SRI calculated using mrsos and mrros were denoted as SSIS and SRIS, respectively. The nonexceedance probabilities of drought variables were computed using an empirical formula:

$$
p\left(x_{t}\right)=\frac{i-0.44}{n+0.12}
$$

where $n$ is the series length, $i$ is the sort rank of $x$, and $p\left(x_{t}\right)$ denotes probability of $x_{t}$. Then the empirical probabilities were transformed into a standardized index $(S I)$ using an inverse Gaussian distribution: So, $S I$ is a Gaussian univariate variable ranging between -3 and +3 .

$$
S I(x)=\phi^{-1}(p)
$$

\subsection{Comprehensive drought Indices scPDSI, SPEI and SPAEI}

To assess the performance of SPI, SSI, and SRI, we also estimated popular, comprehensive drought indices, SPEI, SPAEI, and scPDSI. PET is the key predictor in estimating SPEI and scPDSI. Dai (2011) showed that PET calculated using the Thornwaite method (PET_th) could overestimate the impact of global warming, resulting in over-estimating the severity of droughts than PET estimated from the Penman-Monteith method (PET_pm). Therefore PET_pm estimated from the PenmanMonteith formula of the Food and Agriculture Organization of the United States (FAO) was used 
to estimate SPEI and scPDSI in this study. For more details of Penman-Monteith, one can refer to Zhang et al. (2021a).

SPEI was estimated using the three-parameter log-logistic distribution with the deficit between $P$ and PET as inputs (Ayantobo et al. 2019). SPAEI was estimated using the same method as SPEI, but with the deficit between $P$ and $A E T$ as inputs. scPDSI was calculated with $P, P E T$, and Available water capacity (AWC) (https://daac.ornl.gov/cgi-bin/dsviewer.pl?ds id=569) as inputs. In this study, the scPDSI parameters were calibrated using the complete period (1950-2100), which ensures that the most severe droughts and wet spells observed are included in the calibration period (Dai 2011; Gizaw and Gan 2016; van der Schrier et al. 2013; Wells et al. 2004). scPDSI was proposed by Wells et al. (2004) for overcoming the shortcoming of the original PDSI that may not be representative for diverse climatological regions because its empirical parameters (weighting factors and duration factors) were obtained from averaging values obtained from a few locations in USA (Akinremi et al. 1996; Dai 2011; Gizaw and Gan 2016; Gobena and Gan 2013; Guttman 1991; Wells et al. 2004). scPDSI is estimated using the same method as PDSI but with different empirical parameters. It was estimated from the differences between precipitation and climatically appropriate precipitation $(\hat{P}) . \hat{P}$ represents the demand of the water balance calculated from the water budget based on four variables, evapotranspiration $(E T)$, runoff $(R O)$, loss $(L)$, and recharge $(R)$, and the corresponding potential variables by dividing the soil column into two layers (Zhang et al. 2021a). Weighting factors $(\alpha, \beta, \gamma, \delta)$ are used to represent the effects of the local climate on the four potential variables expressed as $\hat{P}$ for a single month,

$$
\hat{P}=\alpha P E T+\beta P R+\gamma P R O+\delta P L
$$

The weighting factors $(\alpha, \beta, \gamma, \delta)$ were estimated as follow:

$$
\left\{\begin{array}{l}
\alpha_{j}=\overline{E T_{j}} / \overline{P E T_{j}} \\
\beta_{j}=\overline{R_{j}} / \overline{P R_{j}}, j=1,2,3 \mathrm{~L}, 12 \\
\gamma_{j}=\overline{R O_{j}} / \overline{P R O_{j}} \\
\delta_{j}=\overline{L_{j}} / \frac{}{P L_{j}}
\end{array}\right.
$$


where the bar represents the mean value over the calibration period. The moisture departure $(d)$ depicting the difference between precipitation $(P)$ and $\widehat{P}$ was calculated as

$$
d=P-\hat{P}
$$

Because the same $d$ could mean different things at different times and different locations, it prevents a straightforward comparison between different values of $d$ (Wells et al. 2004). To overcome the problem, Palmer (1965) proposed correction factors $K^{\prime}$ and $K$ as given below,

$$
\begin{gathered}
K^{\prime}=1.5 \log _{10}\left(\frac{\frac{\overline{P E T}_{j}+\overline{R_{j}}+\overline{R O_{j}}}{\overline{P_{j}}+\overline{L_{j}}}+2.8}{\overline{D_{j}}}\right)+0.5, j=1,2,3 \mathrm{~L}, 12 \\
K=\frac{17.67 K^{\prime}{ }_{j}}{\sum_{j=1}^{12} \overline{D_{j}} K^{\prime}{ }_{j}}, j=1,2, \mathrm{~L}, 12
\end{gathered}
$$

where $\bar{D}$ is the monthly mean of absolute $d$. The moisture anomaly index $Z$ can be calculated by multiplying $d$ with $K$. Finally, PDSI was calculated as

$$
\begin{gathered}
Z_{j}=d_{j} K_{j} \\
X_{j}=p X_{j-1}+q Z_{j}
\end{gathered}
$$

where $p$ and $q$ are 0.897 and $1 / 3$ derived by Palmer using climatic records from several stations in western Kansas and central Iowa of the United States. But for scPDSI, the climatic characteristic $K$ in Eq. 8 and duration factors in Eq. 9 are replaced with automatically calibrated values based on the historical climatic records in local regions, which makes scPDSI a more representative drought measure (Wells et al. 2004). Therefore, scPDSI is selected in this study. For a given time scale, a drought index value can be discretized into predefined categories that indicate not only the severity of a drought event but also periods of excess moisture availability.

\subsection{Evaluation of SPEI, SCPDSI, and SPAEI in identifying different drought}

\section{types}

Although SPEI, sCPDSI, and SPAEI are commonly used to assess meteorological droughts, they can also be used to assess other types of drought because these indices consider the whole 
atmosphere-land surface water balance processes. Vicente-Serrano et al. (2010a, b), who was the first to propose SPEI, indicated that because of its multi-scalar characteristics, SPEI can identify different drought types, namely, meteorological, hydrological, and agricultural droughts. For example, Potopová et al. (2015) assessed agricultural drought risks using SPEl in the Czech Republic, showing that SPEI is applicable in agricultural drought detection. By comparing SPI, SPEI, SCPDSI, and SPAEI, Joetzjer et al. (2013) demonstrated that SPAEI was better in identifying hydrological droughts than SPI, SPEI and ScPDSI. Since the complete water cycle (precipitation, runoff, evapotranspiration, and soil moisture) Is considered in estimating scPDSI, scPDSI is capable in identifying different drought types. Hence, PDSI (or SCPDSI) has also been used to characterize hydrological (Joetzjer et al. 2013) and agricultural droughts (Ding et al. 2021). To investigate the performance of SPEI, SPAEI, and SCPDSI in identifying different drought types under the impact of climate warming, we estimated the Pearson's correlations between these three drought indices and univariate drought indices (SPI, SSIS, and SRIS) at 1-48 month scales.

\subsection{Assessment of future drought characteristics}

In this study, moderate to extreme droughts of China are our primary focus (PDSI $<-2$, other indices $<-1)$. For each month, grids with PDSI values lower than $-2(-1$ for other indices $)$ are considered as droughts. Drought area is the total area of grids suffering from droughts and drought severity is the average drought index of grid cells experiencing droughts.

\section{Results}

\subsection{Warming across China}

The average temperature across China based on four SSP scenarios shows a strong warming trend, especially after the year 2000 (Online Resource 1, Fig. S1a). Projected temperature based on the four SSPs diverges significantly after the 2050s, with warming starting to slow down or plateau under the more aggressive mitigation scenarios of SSP1-2.6 and SSP2-4.5, but SSP3-7.0 and SSP58.5 continue to project a rapid warming trend after 2050s. From 2071 to 2100 , the median warming 
projected by these scenarios are $2.3{ }^{\circ} \mathrm{K}$ (SSP1-2.6), $3.4{ }^{\circ} \mathrm{K}$ (SSP2-4.5), $4.6^{\circ} \mathrm{K}$ (SSP3-7.0), and 5.3 ${ }^{\circ} \mathrm{K}$ (SSP5-8.5) compared to 1951-1980. Even for the same scenario, because differences in the projected warming between different GCMs can be large (as shown by black dots in Online Resource 1, Fig. S1b), there tends to be a large overlap between adjacent scenarios, especially between SSP3-7.0 and SSP5-8.5, which means that uncertainties of long-term SSP projections across China are fairly large.

\subsection{Meteorological drought}

The mean SPI estimated for two historical (1950-1980 (1960s) and 1985-2014 (2000s)) and two future periods (2040-2070 (2050s) and 2071-2100 (2080s)) are shown in Fig. 2. For the 1960s, the SPI of most northern China (regions 1-5) was under the mild-drought range, while most regions in southern China (regions 6 and 7) were not affected by drought (near-normal range). In contrast to the 1960s, the northwestern desert and north Qinghai-Tibetan Plateau became wetter, changing from a mild drought to near-normal conditions in the 2000s. However, in the 2000s the reverse happened to southern China which became drier, changing from near-normal conditions to mild or even moderate droughts. Under both climate scenarios, all parts of China are projected to become wetter in the 2050s and 2080s. By the end of the 21st century, under the SSP2-4.5 scenario, more than half of China is projected to experience a moderately wet climate, especially in northern China. China could become considerably wetter, with more than $80 \%$ of regions under moderate or extremely wet conditions, such as southern regions of the northwest desert and Qinghai-Tibetan Plateau, which could be very wet. Under climate scenarios corresponding to the highest greenhouse gas emissions, e.g., SSP5-8.5, the Qinghai-Tibetan Plateau could experience high wetting trends, a pattern which was also documented in CMIP5 (Chen and Frauenfeld 2014). In general, precipitation is projected to increase over China under both climate scenarios, as shown by an obvious wetting trend in SPI estimated across China, especially in the Qinghai-Tibetan Plateau under the SSP5-8.5 scenario at the end of the 21 st century. The effect of higher precipitation projected over the Qinghai-Tibetan Plateau could raise the availability of water resources in other regions, as many major rivers of China originate from the Qinghai-Tibetan Plateau, where changes of its spring snow depth and the associated circulations have a significant influence on the East Asian summer monsoon (Zhang et 
al. 2004). The projected wetting trend in the 2050s and 2080s under the SSP5-8.5 scenario is expected to benefit the future agricultural production and to contribute to the environmental conservation of northwestern China of arid climate (Shi et al. 2007).

\subsection{Agricultural drought}

Fig. 3 shows droughts estimated from the near-surface (top panels) and soil column moisture (bottom panels) conditions for two historical (1951-1980, 1985-2014) and two future periods (2041-2070, 2071-2100) under both climate scenarios. Compared to the meteorological drought, the agricultural drought exhibits a widespread pattern in the future, especially in southern China (regions 6 and 7). According to both SSIS and SSPs estimated for the two historical periods, most parts of southern China had experienced near-normal climatic conditions. By the 2050s, southern China (regions 6 and 7) is projected to become drier, resulting in mild to moderate drought conditions in $65 \%$ and $70 \%$ of the land area under SSP2-4.5 and SSP5-8.5, respectively. By the 2080s, more severe and widespread droughts are projected to occur in southern China, and the fraction of land areas suffering from droughts would increase to $84 \%$ and $88 \%$ under SSP2-4.5 and SSP5-8.5 at regions 6 and 7, respectively. In northern China, especially in the northwest desert region (region 1) and northern Qinghai-Tibetan Plateau (region 3), soil moisture is projected to be wetter with increasing trends similar to the projected precipitation trends. By the end of the 21st century, according to the projected SSIS patterns, 40\% (SSP2-4.5) and 62\% (SSP5-8.5) of the northwest desert region would be moderately or even very wet. In the same period, most other regions (regions $2,4,5$ ) are also projected to be exhibit near-normal or moderately wet patterns, but not as wet as that of the projected SPI.

The projected column soil moisture drought based on SSI exhibits a pattern similar to the nearsurface soil moisture drought based on SSIS for the same periods, but with more severe and widespread drying patterns in southern regions and wetter patterns in northern regions, which are also documented in other studies (Cook et al. 2018, 2020). This may be partly attributed to the longer memory of soil moisture deeper in the soil column, where the variability of antecedent soil moisture can persist as it tends to be carried over from previous months, in contrast to the surface soil moisture being more sensitive to changes in current climatic conditions such as precipitation 
and evapotranspiration (Berg and Hall 2017). By the end of the 21st century, most parts of the northwest desert (region 1), Inner Mongolia (region 2), and warm-temperate northern China (region 5) are projected to be moderately or very wet, especially based on the projected soil moisture patterns under the SSP5-8.5 scenario. However, the SSI estimated project severe drought patterns in some regions, such as southern Qinghai-Tibetan Plateau and the northern regions of Northeast China by the end of the 21st century under both SSP2-4.5 and SSP5-8.5 climate scenarios, but not so according to the projected soil moisture patterns based on the estimated SSIS. Some other studies also report major differences in trends between projected surface versus soil column moisture in response to global warming (Cook et al. 2020; Mankin et al. 2017). Additionally, soil columns modeled by different CMIP6 models do not extend to the same maximum depth, which makes intercomparisons of the column soil moisture projected by different climate models difficult even after normalizing the soil column depths of the climate models before comparisons. Despite of discrepancies between climate models, it is still useful to investigate possible severe and widespread drying patterns in both surface and column soil moisture to gain a better understanding of future agricultural droughts in China, instead of only meteorological droughts based on SPI because soil moisture represent the direct source of water for vegetation growth (Cook et al. 2020).

\subsection{Hydrological drought}

Hydrological drought exhibits drought patterns similar to meteorological drought patterns (Fig. 2), with considerably wetter patterns projected across some parts of China in the future compared to the historical periods (Fig. 4). The most obvious wetting trends are projected in some parts of the northwest desert (region 1), Inner Mongolia (region 2), northeastern China (region 4), and warmtemperate northern China (region 5). Most of these regions had modest drought conditions in the 1960s, which gradually changed to near-normal in the 2000s and are projected to be wetter in the 2050s, and eventually become moderately wet by the end of the 21 st century. As expected, these regional changes in hydrological droughts are similar to meteorological droughts, given precipitation is the main driver behind the hydrologic cycle, and therefore the runoff trends. In these northern regions, snow dynamics or changes to snowfall also play an important role, such as a shift to an earlier onset of spring snowmelt, often at the expense of reduced summer runoff due to less 
snowfall and less surface snowpack in response to a warmer climate (Shi and Wang 2015). Under warming, the total precipitation is also projected to increase in these regions, a higher fraction of rainfall over the total precipitation, and higher future spring snowmelt runoff. Under the SSP2-4.5 climate scenario, both SRIS and SRI project a wetter pattern by the end of the 21st century. Under the SSP5-8.5 climate scenario, more than $45 \%$ and $47 \%$ of the regions are projected to be moderately or very wet based on the SRIS and SRI estimated, respectively.

Although some hydrological droughts are projected by the end of the 21 st century in some regions of the Qinghai-Tibetan Plateau according to SRIS (Fig. 4d and h), the projected hydrological drought is less extensive compared to the projected agricultural drought. In contrast, some humid regions (regions 6 and 7) are projected to experience opposite trends in hydrological and agricultural droughts, such that the former changes to wet or near-normal conditions but the latter changes to mild or moderate drought conditions. The opposite projections may be attributed to different physical hydrologic processes that affect the basin runoff and soil moisture (Mankin et al. 2019; Zhang et al. 2014). In other words, different drought indicators could result in different drought assessments for the same regions and so it is generally not advisable to rely only on one drought index to predict the range of possible changes in future physical drought conditions.

\subsection{Comparing Future Droughts based on scPDSI, SPEI and SPAEI}

The mean scPDSI computed for two historical and two future periods are shown in Fig. 5. scPDSI projects more severe drought conditions than meteorological and hydrological drought indices at the end of the 21st century, but is similar to projected agricultural drought patterns, with drying trends projected in southern China and a minor wetting trend projected in northern China. Compared to SSIS, scPDSI projects future drier conditions in the northwest desert region (region 1), Inner Mongolia (region 2), and some northwestern regions of Qinghai-Tibetan Plateau (region 3) for the historical periods. In 1960s, $61 \%(71 \%)$ and $65 \%$ (79\%) of region 1 (region 2) were under moderate (mild) drought conditions, respectively under SSP2-4.5 and SSP5-8.5 (Fig. 5a and e). In the same period, most parts of region 1 (region 2) were under mild (near-normal) drought conditions according to SSIS (Fig. 3a and e). In the 2000s, scPDSI still indicates a slightly drier condition than SSIS in the northwest desert region (region 1), Inner Mongolia (region 2), and some western regions 
of Qinghai-Tibetan Plateau (region 3), but most other regions are under near-normal conditions, which is similar to drought conditions based on SSIS. For both future periods, northern China is projected to be wetter while southern China is to become drier. In 2080s, 60\% (58\%) and 71\% (68\%) of region 1 (region 2) are expected to be under mild or wetter conditions, respectively under SSP24.5 and SSP5-8.5 (Fig. 5d and h). In the same period, $83 \%$ and $70 \%$ of the southern humid regions (regions 6 and 7) are projected to be under mild or more severe dry conditions, which are marginally less than the areas of drought based on SSIS (Fig. 3d and h). On the other hand, most parts of northern China and northeastern China of temperate climate are projected to be under near-normal conditions by the end of the 21 st century, similar to SSIS.

Fig. 6 shows the mean SPEI computed for two historical and two future periods. According to SPEI, almost all regions across China are projected to be drier from the 1950s to 2080s, which has also been documented in previous studies based on CMIP5 climate scenarios (Yao et al. 2020). Drought patterns based on SPEI project that northwestern China and Inner Mongolia will be invaded by more intense droughts in 2050s and 2080s (Fig. 6). The future drought conditions of China based on SPEI are opposite to results obtained from the aforementioned drought indices, which generally project a wetting trend in these arid regions. This discrepancy between future droughts of China projected by SPEI compared to those based on other drought indices may be attributed to climatic conditions in arid regions, where $P E T$ is mostly expected to be much higher than $A E T$ which is more dependent on precipitation than PET. Therefore, SPEI could produce biased drought patterns, especially in regions where PET is always higher than precipitation and AET (Yang et al. 2018a; Yang et al. 2018b). With temperature and net radiation projected to increase significantly in arid regions of China, the $P E T$ is projected to increase more than precipitation, resulting in more frequent and severe future droughts projected by SPEI in arid regions of China. Therefore the relationship between PET and precipitation (P-PET, or P/PET) should be more meaningful spatially (climatologically describing aridity condition), but less meaningful temporally, in characterizing drought conditions (Zhang et al. 2019a).

Fig. 7 shows the mean SPAEI patterns for two historical and two future periods. SPAEI, based on AET rather than PET, projects a wetting trend in the 21 st century, which is similar to projected hydrological drought patterns (Fig. 4). By the end of the 21 st century, most regions (76\%) of China 
are projected to be under near-normal conditions under the SSP2-4.5 scenario, and most regions (63\%) are expected to be under mild wet conditions under the SSP5-8.5 scenario. And almost no regions are projected to be under drought conditions, except for the Hainan province, which is projected to be under mild drought conditions. Compared to SPEI and scPDSI, SPAEI projects a smoother transition between drought conditions of different periods. No severe drought or wet conditions are projected by the averaged SPAEI.

As precipitation is the most important driver of meteorological droughts which is also related to the atmospheric water demand (Mckee et al. 1993; Stagge et al. 2017), it is worth comparing meteorological drought conditions estimated from scPDSI, SPEI, and SPAEI. Fig. 8 shows the correlations $(r)$ between spatially averaged SPI and scPDSI, SPEI, and SPAEI from the seven climatic regions of China at 1- to 48 -month time scales.

The $r$ values for SPAEI-SPI are generally higher than 0.6 in arid regions (regions 1 and 2), and higher than 0.8 in humid and semi-humid regions, which are generally higher than $r$ values for scPDSI-SPI and SPEI-SPI. The $r$ values for scPDSI-SPI are generally higher than 0.3 at the nonhumid region (regions 1-5), which are always higher than those for SPEI-SPI at long time scales (> 10 months). By contrast, the $r$ values for SPEI-SPI are generally higher $(0.12-0.95$; average $=0.60$ under SSP2-4.5 and 0.47 under SSP5-8.5) than those for scPDSI-SPI $(0-0.33$; average $=0.30$ under SSP2-4.5 and 0.18 under SSP5-8.5) in central and southern China (regions 6 and 7).

These results suggest that SPAEI and sc-PDSI are likely better than SPEI in monitoring meteorological droughts in arid and semi-arid regions, especially for investigating long-term droughts, which inevitably are the primary interest to most countries coping with the long-term impact of droughts which in recent years have been occurring more frequently and in greater severity. For China, $r$ values for scPDSI-SPI increase with time scales of 12-15 months but then decrease with higher time scales. Therefore, scPDSI is likely more suitable than SPEI in identifying droughts in China lasting more than a year, and the performance tends to be more robust in arid and semi-arid areas. The $r$ values for SPAEI-SPI are similar to those for scPDSI-SPI, but higher than those for SPEI-SPI in northwest arid regions. The $r$ values for scPDSI-SPI are lower in southern humid regions for droughts of short-term time scales. When the time scale of droughts is longer than 12-month, SPEI tends to perform poorly even in humid regions, which shows that SPEI is 
incapable of identifying long-term meteorological drought. In addition, the effectiveness of SPEI in identifying future meteorological droughts is also dependent on climate scenarios. For example, the $r$ values for SPEI-SPI under SSP5-8.5 are considerably less than those under SSP2-4.5 in all regions. This should be attributed to the larger increase in temperature projected under the SSP5-8.5 climate scenario (Online Resource 1, Fig. S1), which lead to a larger difference between $P$ and $P E T$, and SPEI tends to overestimate droughts with higher PET, especially in non-humid regions, where PET can be considerably higher than $A E T$. Therefore, it seems SPAEI and scPDSI are more suitable than SPEI in identifying meteorological droughts in arid regions. In humid or semi-humid regions, SPAEI performs better than other indices in monitoring meteorological droughts.

To better understand the performance of scPDSI, SPEI, and SPAEI in evaluating agricultural droughts, the correlations between scPDSI and SSIS, SPAEI and SSIS, and SPEI and SSIS were investigated. Fig. 9 shows the $r$ values of scPDSI-SSIS, SPEI-SSIS, and SPAEI-SSIS at 1 - to 48month scales in seven climate regions of China. At climatic regions 1 and 2, the $r$ values for scPDSISSIS (average $=0.35$ under SSP2-4.5, and average $=0.41$ under SSP5-8.5) and SPAEI-SSIS are generally higher than those for SPEI-SSIS at all time scales. The $r$ values for scPDSI-SSIS in climatic region 3 (average $=0.33$ under SSP2-4.5 and average $=0.31$ under SSP5-8.5) are marginally lower than those in climatic regions 1 and 2. In the same regions, the $r$ values for SPEISSIS under SSP2-4.5 show a higher range $(0.32-0.38)$ than those for scPDSI-SSIS $(0.24-0.38)$ at long time scales ( $>12$-month), but the $r$ values for SPEI-SSIS under SSP5-8.5 (average $=0.23$ ) are generally lower than those for scPDSI-SSIS (average $=0.32$ ). It seems SPAEI is less effective in identifying agricultural droughts in this climatic region than scPDSI and SPEI. At regions 4 and 5, the $r$ values for SPEI-SSIS are similar to those in climatic region 3, which are higher $(0.30-0.55)$ than those for scPDSI-SSIS $(0.22-0.52)$ at longer time scales (> 12-month) under SSP2-4.5 but are lower under the SSP5-8.5 scenario at all time scales (0.01-0.35 for SPEI vs. $0.34-0.45$ for scPDSI). SPEI outperforms scPDSI and SPAEI in humid regions (regions 6 and 7) at almost all-time scales under both scenarios, with $r$ values of $0.46-0.60$ at climatic region 6 , and $0.44-0.58$ at climatic region 7. The performance of scPDSI decreases at time scales beyond 12-month scale in these regions, in comparison with the performance of SPEI, which likely means that SPEI is more suitable in identifying agricultural droughts in humid regions of China but scPDSI is better or more robust 
in identifying agricultural droughts in drier climatic regions of China.

Correlations between scPDSI and SRIS, between SPEI and SRIS, and between SPAEI and SRIS were also examined to evaluate the performance of these three drought indices in identifying hydrological droughts of China. Fig. 10 shows the relationship for scPDSI-SRIS, SPEI-SRIS, and SPAEI-SRIS at 1- to 48-month scales at seven climate regions of China. SPAEI outperforms scPDSI and SPEI in identifying hydrological droughts in the 7 climatic regions at 1 - to 48 -month scales, with an averaged $r$ value of 0.62 scPDSI is less effective in identifying meteorological and agricultural droughts in northwestern China and Inner Mongolia (climatic regions 1 and 2), with $r$ values ranging from 0.17 to 0.32 . At Qinghai-Tibetan region (region 3), the $r$ values for SPEI-SSIS under SSP2-4.5 show a higher range (average $=0.37$ ) than those for scPDSI-SSIS (average $=0.27$ ) when time scale is more than 12 months, but the $r$ values for SPEI-SSIS under SSP5-8.5 (averaged 0.26) are generally slightly higher than that for scPDSI-SSIS (0.24). Again, SPEI performs better than scPDSI in humid regions (regions 6 and 7) virtually at all time scales under both SSP climate scenarios. Similar to its performance in identifying meteorological or agricultural droughts, the performance of scPDSI decreases with time scales beyond 12-month, and it tends to be poorer than the performance of SPEI. Therefore, it seems that SPAEI is more effective in identifying hydrological droughts in both humid and arid regions, SPEI is better than scPDSI in identifying hydrological droughts in humid regions, but scPDSI is better than SPEI in identifying hydrological droughts in drier regions.

\subsection{Temporal variations of drought areas and severity}

From the above analysis, scPDSI shows more robust performance in identifying agricultural droughts, especially in non-humid or arid regions. Therefore, it is chosen to further analyze the evolution of drought characteristics in China. SSIS is also selected to analyze the drought characteristics of these regions together with scPDSI. Fig. 11 shows the time series of drought areas at seven regions based on scPDSI and SSIS. In northwestern China and Inner Mongolia (regions 1 and 2), drought areas estimated from scPDSI and SSIS both show an obvious decreasing trend. In region 1, drought areas based on scPDSI (SSIS) decrease from 60.1\% (26.2\%) in 1960s to $8.7 \%$ 
scenarios. In region 2, drought areas based on scPDSI (SSIS) decrease from 33.4\% (23.7\%) in 1960s to $7.6 \%(6.9 \%)$ in 2080 s under SSP2-4.5 and from $37.3 \%$ (24.9\%) to $6.3 \%(3.5 \%)$ under SSP5-8.5 climate scenarios. In Qinghai-Tibetan Plateau (region 3), drought areas decrease sharply before the 2000s, then increase slightly, but drought areas in the 2080s (17.7\% and $19.0 \%$ for scPDSI under SSP2-4.5 and SSP5-8.5; $12.3 \%$ and 19.0\% for SSIS under SSP2-4.5 and SSP5-8.5) are substantially below those in 1960s (35.5\% and 38.6\% for scPDSI under SSP2-4.5 and SSP5-8.5; $24.2 \%$ and $24.1 \%$ for SSIS under SSP2-4.5 and SSP5-8.5). Drought areas based on scPDSI are generally higher than those based on SSIS. The overestimation of drought based on ScPDSI has also been reported in studies conducted in other climatic regions (Hoerling et al. 2012; Swann et al. 2016).

At humid regions (regions 6 and 7), drought areas based on scPDSI and SSIS tend to increase significantly over time. In region 6 , drought areas based on scPDSI (SSIS) increase from $4.6 \%$ (4.8\%) in 1960 s to $44.1 \%$ (39.3\%) in 2080s under SSP2-4.5 and from $4.0 \%$ (5.0\%) to $37.3 \%$ (46.7\%) under SSP5-8.5 climate scenarios. In region 7, drought areas based on scPDSI (SSIS) increase from $4.5 \%(3.1 \%)$ in 1960 s to $50.5 \%(37.8 \%)$ in 2080 s under SSP2-4.5 and from $1.4 \%(3.4 \%)$ to $45.2 \%$ (34.5\%) under SSP5-8.5. In regions 4 and 5, drought areas are projected to decrease slightly, by an average of $15 \%$ from the 1960s to 2080s. Apparently, drought areas obtained from scPDSI in humid regions generally agree better (higher correlations) with SSIS than that in arid and semi-arid regions.

Due to differences in the range of drought severities estimated from scPDSI and SSIS, it is difficult to directly compare the drought severities estimated from these two indices. Therefore, the time series of drought severities in seven regions obtained from scPDSI and SSIS are separately shown in Fig. 12 and Fig. 13. The drought severity based on scPDSI shows a decreasing trend before the 2050s but an increasing trend after 2050s in northwestern China, with an average scPDSI of -3.0 (moderate drought) by the end of the 21 st century. In the same region, drought severity based on SSIS shows a decreasing trend, with an average value of -0.8 (minor drought) by the end of the 21st century. Drought severity based on scPDSI and SSIS both show a decreasing trend at Inner Mongolia, with average values of 1.8 (minor drought) and 0.6 (minor drought) respectively for scPDSI and SSIS by the end of the 21st century. At the Qinghai-Tibetan Plateau, the drought severity based on scPDSI shows an increasing trend after 2015 at a rate higher than SSIS. In humid regions (regions 6 and 7), both severity time series based on scPDSI and SSIS show an obvious 
increasing trend, with average values of -3.0 and 1.4 respectively for scPDSI and SSIS by the end of the 21 st century. In humid regions, drought severity and drought areas based on scPDSI and SSIS both show obvious increasing trends, which likely means that these regions will experience more severe dry spells compared to historical periods. Similar to drought areas, drought severity has no obvious trend in semi-humid regions of China (regions 4 and 5). Drought severity obtained from scPDSI agrees better with that from SSIS in humid regions, which is similar to drought areas.

\section{Discussion of Results}

It is beneficial to understand how the occurrence of different types of droughts will change under the impact of climate change. We investigated drought responses to warming under SSP2-4.5 and SSP5-8.5 climate scenarios using outputs from GCMs of CMIP6 in seven climatic regions across China. Three types of univariate drought indices based on projected precipitation, soil moisture, and runoff were used to investigate future drought conditions, including all three traditional drought types - meteorological, hydrological, and agricultural droughts. In addition, three popular drought indices, scPDSI, SPEI, and SPAEI, were also estimated to compare the projected drought patterns of China in the 2050s and 2080s with these three types of univariate drought indices. Finally, drought areas and severity were also analyzed using scPDSI and SSIS for 7 climatic regions of China. In this study, we only estimated SPI, SPEI, and scPDSI patterns using original meteorological variables (precipitation, temperature, etc.) simulated by GCMs so that we can compare these indices with SRI and SSI estimated from soil moisture and runoff data of GCMs, which are difficult to be downscaled due to the lack of observed data to develop empirical relationships between simulated and observed data. To assess the validity of using original GCM data in the drought analysis, we have compared meteorological data (precipitation and temperature) anomaly at 7 climatic regions and drought patterns (SPI and SPEI) derived from original GCM simulations with those derived from statistically downscaled GCM simulations by the BCSD method from 1979 to 2100 (Online Resource 1, Fig. S2-Fig. S5). The downscaled precipitation and temperature show a similar increasing trend to the original GCM precipitation (Online Resource 1, Fig. S2 and Fig. S3). Drought indices (SPI and SPEI) estimated using original GCM simulations also have similar patterns with those estimated using statistically downscaled GCM simulations at 
three periods (the 2000s, 2050s, and 2080s) (Online Resource 1, Fig. S4 and Fig. S5). Therefore, we expect the projected changes to meteorological, hydrological, and agricultural droughts based on the original GCM data to be generally representative.

Based on results obtained from different drought indices except for SPEI, it seems that northern arid China is expected to become wetter. Projected meteorological and hydrological droughts consistently show that most parts of China will become wetter in the future. This is mainly attributed to the increase of precipitation. Under a warmer climate, the atmospheric moisture is expected to be higher as the near-surface atmospheric water holding capacity will increase at about $7 \%$ per ${ }^{\circ} \mathrm{C}$ of warming (Clausius-Clapeyron scaling) (Zhang et al. 2021a). Further, the possible convergence of storm systems could also result in higher rainfall totals during wet events. According to CMIP6 models, the global annual mean precipitation over land, especially at high latitudes of the Northern Hemisphere will increase. Under both SSP scenarios, precipitation increases faster in winter than that in summer, especially in northern China (Online Resource 1, Fig. S6). On the other hand, under a warmer climate in some cold and alpine regions of China, the snowpack will decrease partly due to less snowfall and higher spring snowmelt runoff, which together with higher evaporative losses will result in less summer runoff in these regions. Compared to meteorological and hydrological droughts, agricultural drought is widespread by 2080s in southern China, which is consistent with results obtained using the scPDSI index. This may be partly attributed to the increase in water vapor deficit (Dai et al. 2018) and greater water use by vegetation (Mankin et al. 2019) under global warming.

By correlating univariate drought indices SPI, SRIS, and SSIS with scPDSI, SPEI, and SPAEI of various time scales, it seems that SPAEI and scPDSI can better identify different drought types of China than SPEI, in arid or semi-arid zones. However, the performance of scPDSI decreases at time scales longer than 12-month and it tends to overestimate the extent of drought areas and severity in regions affected by agricultural droughts. This could be attributed to scPDSI not accounting for complicated biological factors and complex processes of soil-vegetation-atmosphere transfer, and without considering the effect of increased $\mathrm{CO}_{2}$ concentration on plant stomatal conductance in a warmer climate (Frierson and Scheff 2014).

In arid and semi-arid regions, PET is mostly much higher than AET which represents the 
atmospheric water demand. However, in these regions, it is precipitation rather than PET that determines AET (Online Resource 1, Fig. S7). On the other hand, in humid regions, the change in AET is more dependent on PET than on precipitation. Because of differences in the relationships between precipitation, $A E T$, and PET at different climate zones, SPEI which uses the difference between precipitation and $P E T$ in estimating surface water deficit/surplus could overestimate droughts (Zhang et al. 2019a). In general, using $\hat{P}$ as the water demand metric is physically more reasonable than PET in estimating the surface water-energy balance, especially in arid regions.

Using SPEI, we could over-project the severity of droughts in China by the end of the 21 st century because PET is higher under climate warming impact. Vicente-Serrano et al. (2015) evaluated the sensitivity of four drought indices to precipitation and PET inputs and found that PDSI shows the lowest sensitivity to precipitation and PET, while SPEI shows the largest sensitivity to variations in $P E T$, especially in non-humid (water-limited) regions. Our results also show that using only one drought index may not accurately represent the range of possible changes in future droughts (Taylor et al. 2013), the evolvement of future droughts is also dependent on the types of droughts considered, whether it is meteorological, agricultural or hydrological droughts. Generally, SPAEI is better in identifying meteorological and hydrological droughts, while scPDSI is better in identifying agricultural droughts in China. Apparently, SPEI would overestimate droughts in arid regions and so it should be used with caution.

\section{Summary and Conclusions}

We analyzed changes in meteorological (SPI), hydrological (SRI, SRIS), and agricultural (SSI, SSIS) droughts of China using outputs of GCMs of the $6^{\text {th }}$ Coupled Model Intercomparison Project (CMIP6) under SSP2-4.5 and SSP5-8.5 climate scenarios, and compared those with popular offline drought indices, namely, scPDSI, SPEI, SPI, and SPAEI. The key conclusions are as follows:

1. Precipitation is projected to increase over China, with a clear increasing trend in meteorological drought based on SPI, especially in the Qinghai-Tibetan Plateau under the SSP5-8.5 scenario at the end of the 21 st century. 
2. The agricultural drought in southern China estimated from soil moisture data is projected to be more severe and widespread by the end of the 21 st century. In contrast, soil moisture is projected to be wetter with increasing trends similar to precipitation trends in northern China, especially in the northwest desert region and northern Qinghai-Tibetan Plateau.

3. Hydrological droughts, similar to meteorological droughts, are projected to exhibit considerably wetter patterns over parts of China, with the most obvious wetting trends projected in some parts of the northwest desert, Inner Mongolia, northeastern China, and warm-temperate northern China.

4. Compared to SPEI, SPAEI and scPDSI can better represent meteorological droughts, hydrological droughts, and agricultural droughts of China, especially in non-humid regions. Furthermore, SPAEI outperforms scPDSI in identifying meteorological and hydrological droughts.

5. In arid northwestern China and Inner Mongolia, drought areas and severity are projected to decrease by both scPDSI and SSIS. In contrast, in humid regions of China, drought areas and severity are projected to increase significantly by both scPDSI and SSIS with higher correlations than their respective projections in arid and semi-arid regions of China.

Acknowledgments The first author was financially supported by the National Natural Science Foundation of China (nos. 51879222 and 52079111), the China Scholarship Council (nos. 201906300059).

Author contribution Lead author GZ designed the study, performed the analysis and wrote the paper. TG and XS provided essential assistance in the analysis, writing, and revision stages.

Availability of data CMIP6 data are available online (https://esgf-node.llnl.gov/projects/cmip6/).

\section{Declarations}

Conflict of interests The authors declare no competing interests.

\section{References}


Akinremi OO, McGinn SM, Barr AG (1996) Evaluation of the Palmer Drought Index on the Canadian prairies. J Clim 9(5): 897-905. https://doi.org/10.1175/15200442(1996)009<0897:EOTPDI>2.0.CO;2

American Meteorological Society (AMS) (2013) Drough—an information statement. [https://www.ametsoc.org/ams/index.cfm/about-ams/ams-statements/statements-of-the-ams-inforce/ drought/]

Ayantobo OO, Li Y, Song S (2019) Multivariate drought frequency analysis using four-variate symmetric and asymmetric archimedean copula functions. Water Resour Manag 33: 103-127. https://doi.org/10.1007/s11269-018-2090-6

Ayantobo OO, Wei J (2019) Appraising regional multi-category and multi-scalar drought monitoring using Standardized Moisture Anomaly Index (SZI): A water-energy balance approach. J Hydrol 579: 124139. https://doi.org/10.1016/j.jhydrol.2019.124139

Berg A, Findell K, Lintner B (2016) Land-atmosphere feedbacks amplify aridity increase over land under global warming. Nat Clim Chang 6(9): 869-874. https://doi.org/10.1038/nclimate3029

Berg N, Hall A (2017) Anthropogenic warming impacts on California snowpack during drought. Geophys Res Lett 44(5): 2511-2518. https://doi.org/10.1002/2016g1072104

Chen L, Frauenfeld OW (2014) A comprehensive evaluation of precipitation simulations over China based on CMIP5 multimodel ensemble projections. J Geophys Res Atmos 119(10): 5767-5786. https://doi.org/10.1002/2013JD021190

Chen S, Gan TY, Tan X, Shao D, Zhu J (2019) Assessment of CFSR, ERA-Interim, JRA-55, MERRA-2, NCEP-2 reanalysis data for drought analysis over China. Clim Dyn 53(1-2): 737757. https://doi.org/10.1007/s00382-018-04611-1

Cheng Q, Gao L, Chen Y, Liu M, Deng H, Chen X (2018) Temporal-spatial characteristics of drought in Guizhou province, China, based on multiple drought indices and historical disaster records. Adv Meteorol 2018: 4721269. https://doi.org/10.1155/2018/4721269

Cook BI, Mankin JS, Anchukaitis KJ (2018) Climate change and drought: From past to future. Curr Clim Change Rep 4(2): 164-179. https://doi.org/10.1007/s40641-018-0093-2

Cook BI, Mankin JS, Marvel K, Williams AP, Smerdon JE, Anchukaitis KJ (2020) Twenty-first century drought projections in the CMIP6 forcing scenarios. Earth Future 8: 1-20. 
https://doi.org/10.1029/2019EF001461

Dai A (2011) Characteristics and trends in various forms of the Palmer Drought Severity Index during 1900-2008. J Geophys Res 116: D12115. https://doi.org/10.1029/2010jd015541

Dai A, Zhao T, Chen J (2018) Climate change and drought: A precipitation and evaporation perspective. Curr Clim Change Rep 4(3): 301-312. https://doi.org/10.1007/s40641-018-0101-6

Ding Y, Gong X, Xing Z, Cai H, Zhou Z, Zhang D, Sun P, Shi H (2021) Attribution of meteorological, hydrological and agricultural drought propagation in different climatic regions of China. Agric Water Manag 255: 106996. https://doi.org/10.1016/j.agwat.2021.106996

Douville, H., Krishnan, R., Renwick, J., Allan, R., Arias, P., Barlow, M., CerezoMota, R., Cherchi, A., Gan, T. Y., et al., 2021, Water Cycle Change, In: Climatic Change, 2021: the physical science basis. Contribution of Working Group I to 6th Assessment Report of IPCC, Masson-Delmotte, et al., (Eds.), Cambridge U. Press.

Eyring V, Bony S, Meehl GA, Senior CA, Stevens B, Stouffer RJ, Taylor KE (2016) Overview of the Coupled Model Intercomparison Project Phase 6 (CMIP6) experimental design and organization. Geosci Model Dev 9(5): 1937-1958. https://doi.org/10.5194/gmd-9-1937-2016

Frierson DMW, Scheff J (2014) Scaling potential evapotranspiration with greenhouse warming. J Clim 27(4): 1539-1558. https://doi.org/10.1175/jcli-d-13-00233.1

Frierson DMW, Scheff J (2015) Terrestrial aridity and its response to greenhouse warming across CMIP5 Climate Models. J Clim 28(14): 5583-5600. https://doi.org/10.1175/jcli-d-14-00480.1

Gizaw MS, Gan TY (2016) Impact of climate change and El Niño episodes on droughts in subSaharan Africa. Clim Dyn 49(1-2): 665-682. https://doi.org/10.1007/s00382-016-3366-2

Gobena A, Gan TY (2013) Assessment of trends and possible climate change impacts on summer moisture availability in western Canada based on metrics of the Palmer Drought Severity Index. J Clim 26(13): 4583-4595. https://doi.org/10.1175/JCLI-D-12-00421.1

Guttman NB (1991) A sensitivity analysis of the Palmer hydrologic drought index. J Am Water Resour Assoc 27: 797-807. https://doi-org.login.ezproxy.library.ualberta.ca/10.1111/j.17521688.1991.tb01478.x

Hao Z, AghaKouchak A (2013) Multivariate Standardized Drought Index: A parametric multi-index model. Adv Water Resour 57: 12-18. https://doi.org/10.1016/j.advwatres.2013.03.009 
Hoerling M, Eischeid J, Perlwitz J, Quan X, Zhang T, Pegion P (2012) On the increased frequency of Mediterranean drought. J Clim 25(6): 2146-2161. https://doi.org/10.1175/JCLI-D-1100296.1

Joetzjer E, Douville H, Delire C, Ciais P, Decharme B, Tyteca S (2013) Hydrologic benchmarking of meteorological drought indices at interannual to climate change timescales: A case study over the Amazon and Mississippi river basins. Hydrol Earth Syst Sci 17(12): 4885-4895. https://doi.org/10.5194/hess-17-4885-2013

Liu SN, Shi HY, Sivakumar, B (2020) Socioeconomic drought under growing population and changing climate: A new index considering the resilience of a regional water resources system. J Geophys Res Atmos 125(15): e2020JD033005. https://doi.org/10.1029/2020JD033005

Mankin JS, Seager R, Smerdon JE, Cook BI, Williams AP (2019) Mid-latitude freshwater availability reduced by projected vegetation responses to climate change. Nat Geosci 12(12): 983-988. https://doi.org/10.1038/s41561-019-0480-x

Mankin JS, Smerdon JE, Cook BI, Williams AP, Seager R (2017) The curious case of projected twenty-first-century drying but greening in the American West. J Clim 30(21): 8689-8710. https://doi.org/10.1175/jcli-d-17-0213.1

Mckee TB, Doesken NJ, Kleist J (1993) The relationship of drought frequency and duration to time scales. In: Proceedings of the 8th conference on applied climatology, vol 17, no 22. American Meteorological Society, Boston, pp 179-183

Mehran A, Mazdiyasni O, AghaKouchak A (2015) A hybrid framework for assessing socioeconomic drought: Linking climate variability, local resilience, and demand. J Geophys Res Atmos 120(15): 7520-7533. https://doi.org/10.1002/2015JD023147

Mishra AK, Singh VP (2010) A review of drought concepts. J Hydrol 391(1-2): 202-216. https://doi.org/10.1016/j.jhydrol.2010.07.012

Nalbantis I, Tsakiris G (2008) Assessment of hydrological drought revisited. Water Resour Manag 23(5): 881-897. https://doi.org/10.1007/s11269-008-9305-1

O’Neill BC, Kriegler E, Riahi K, Ebi KL, Hallegatte S, Carter TR, Mathur R, van-Vuuren DP (2013) A new scenario framework for climate change research: The concept of shared socioeconomic pathways. Clim Change 122(3): 387-400. https://doi.org/10.1007/s10584-013-0905-2 
Palmer WC (1965) Meteorological drought. US Department of Commerce, Weather Bureau, Washington, DC

Potopová V, Štěpánek P, Možný M, Türkott L, Soukup J (2015) Performance of the Standardised Precipitation Evapotranspiration Index at various lags for agricultural drought risk assessment in the Czech Republic. Agric and For Meteorol 202: 26-38. https://dx.doi.org/10.1016/j.agrformet.2014.11.022

Roderick ML, Greve P, Farquhar GD (2015) On the assessment of aridity with changes in atmospheric $\mathrm{CO}_{2}$. Water Resour $\quad$ Res 54(7): 5450-5463. https://doi.org/10.1002/2015wr017031

Scheepers H, Wang J, Gan TY, Kuo CC (2018) The impact of climate change on inland waterway transport: effects of low water levels on the Mackenzie River. J Hydrol 566: 285-298. https://doi.org/10.1016/j.jhydrol.2018.08.059

Shi HX, Wang CH (2015) Projected 21st century changes in snow water equivalent over Northern Hemisphere landmasses from the CMIP5 model ensemble. Cryosphere 9(5): 1943-1953. https://doi.org/10.5194/tc-9-1943-2015

Shi Y, Shen Y, Kang E, Li D, Ding Y, Zhang G, Hu R (2007) Recent and future climate change in northwest China. Clim Change 80: 379-393. https://doi.org/10.1007/s10584-006-9121-7

Stagge JH, Kingston DG, Tallaksen LM, Hannah DM (2017) Observed drought indices show increasing divergence across Europe. Sci Rep 7(1): 14045. https://doi.org/10.1038/s41598-017$14283-2$

Swann AL, Hoffman FM, Koven CD, Randerson JT (2016) Plant responses to increasing $\mathrm{CO}_{2}$ reduce estimates of climate impacts on drought severity. Proc Natl Acad Sci USA 113(36): 10019-10024. https://doi.org/10.1073/pnas.1604581113

Taylor IH, Burke E, McColl L, Falloon PD, Harris GR, McNeall D (2013) The impact of climate mitigation on projections of future drought. Hydrol Earth Syst Sci 17(6): 2339-2358. https://doi.org/10.5194/hess-17-2339-2013

Taylor KE, Stouffer RJ, Meehl GA (2012) An overview of CMIP5 and the experiment design. Bull Amer Meteorol Soc 93(4): 485-498. https://doi.org/10.1175/bams-d-11-00094.1

van der Schrier G, Barichivich J, Briffa KR, Jones PD (2013) A scPDSI-based global data set of 
dry and wet spells for 1901-2009. J Geophys Res Atmos 118(10): 4025-4048. https://doi.org/10.1002/jgrd.50355

Vicente-Serrano SM, Beguería S, López-Moreno JI (2010a) A multiscalar drought index sensitive to global warming: The Standardized Precipitation Evapotranspiration Index. J Clim 23(7): 1696-1718. https://doi.org/10.1175/2009jcli2909.1

Vicente-Serrano SM, Beguería S, López-Moreno JI, Angulo M, Kenawy AE (2010b) A new global $0.5^{\circ}$ gridded dataset (1901-2006) of a multiscalar drought index: Comparison with current drought index datasets based on the Palmer Drought Severity Index. J Hydrometeorol 11(4): 1033-1043. https://doi.org/10.1175/2010JHM1224.1

Vicente-Serrano SM, Van der Schrier G, Beguería S, Azorin-Molina C, Lopez-Moreno JI (2015) Contribution of precipitation and reference evapotranspiration to drought indices under different climates. J Hydrol 526: 42-54. https://doi.org/10.1016/j.jhydrol.2014.11.025

Wang A, Bohn TJ, Mahanama SP, Koster RD, Lettenmaier DP (2009) Multimodel ensemble reconstruction of drought over the continental United States. J Clim 22(10): 2694-2712. https://doi.org/10.1175/2008JCLI2586.1

Wells N, Goddard S, Michaelsen J (2004) A Self-Calibrating Palmer Drought Severity Index. J Clim 17(12): 2335-2351. $\quad$ https://doi.org/10.1175/15200442(2004)017<2335:ASPDSI>2.0.CO;2

Yang Y, Gan TY, Tan X (2020a) Spatiotemporal changes of drought characteristics and their $\begin{array}{llllll}\text { dynamic drivers in } & \text { Canada. Atmos }\end{array}$ https://doi.org/10.1016/j.atmosres.2019.104695

Yang Y, Roderick ML, Zhang S, McVicar TR, Donohue RJ (2018a) Hydrologic implications of vegetation response to elevated $\mathrm{CO}_{2}$ in climate projections. Nat Clim Chang 9(1): 44-48. https://doi.org/10.1038/s41558-018-0361-0

Yang Y, Zhang S, McVicar TR, Beck HE, Zhang Y (2018b) Disconnection between trends of atmospheric drying and continental runoff. Water Resour Res 54(7): 4700-4713. https://doi.org/10.1029/2018wr022593

Yang Y, Zhang S, Roderick ML, McVicar TR, Yang D, Liu W, Li X (2020b) Comparing Palmer Drought Severity Index drought assessments using the traditional offline approach with direct 

701

Yao N, Li L, Feng P, Feng H, Liu DL, Liu Y, Jiang K, Hu X, Li Y (2020) Projections of drought characteristics in China based on a Standardized Precipitation and Evapotranspiration Index and

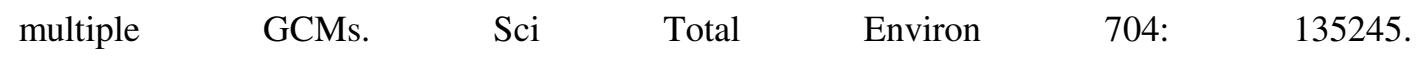
https://doi.org/10.1016/j.scitotenv.2019.135245

Yuan X, Ma Z, Pan M, Shi C (2015) Microwave remote sensing of short-term droughts during crop growing seasons. Geophys Res Lett 42(11): 4394-4401. https://doi.org/10.1002/2015gl064125

Zhang B, Kouchak AA, Yang Y, Wei J, Wang G (2019a) A water-energy balance approach for multi-category drought assessment across globally diverse hydrological basins. Agric For Meteorol 264: 247-265. https://doi.org/10.1016/j.agrformet.2018.10.010

Zhang B, Xia Y, Huning LS, Wei J, Wang G, AghaKouchak A (2019b) A framework for global multicategory and multiscalar drought characterization accounting for snow processes. Water Resour Res 55: 9258-9278. https://doi.org/10.1029/2019WR025529

Zhang G, Su X, Singh VP, Ayantobo OO (2021a) Appraising Standardized Moisture Anomaly Index (SZI) in drought projection across China under CMIP6 forcing scenarios. J Hydrol Reg 37: 100898. https://doi.org/10.1016/j.ejrh.2021.100898

Zhang G, Su X, Ayantobo OO, Feng K (2021b) Drought monitoring and evaluation using ESA CCI and GLDAS-Noah soil moisture datasets across China. Theor Appl Climatol 144: 1407-1418. https://doi.org/10.1007/s00704-021-03609-w

Zhang L, Xiao J, Li J, Wang K, Lei L, Guo H (2012) The 2010 spring drought reduced primary productivity in southwestern China. Environ Res Lett 7(4): 045706. https://doi.org/10.1088/1748-9326/7/4/045706

Zhang X, Tang Q, Zhang X, Lettenmaier DP (2014) Runoff sensitivity to global mean temperature change in the CMIP5 Models. Geophys Res Lett 41(15): 5492-5498. https://doi.org/10.1002/2014g1060382

Zhang Y, Li T, Wang B (2004) Decadal change of the spring snow depth over the Qinghai-Tibetan Plateau: The associated circulation and influence on the East Asian summer monsoon. J Clim 17: 2780-2793. https://doi.org/10.1175/1520-0442(2004)017<2780:DCOTSS>2.0.CO;2 


\section{Figures Title}

Fig. 1 The digital elevation model (DEM) and seven climatic regions of China (Zhang et al. 2021a) Fig. 2 Averaged SPI estimated for China in two historical, 1951-1980 (1960s), 1985-2014 (2000s) and two future, 2041-2070 (2050s) and 2071-2100 (2080s), periods under SSP2-4.5 (a-d) and SSP58.5 climate scenarios (e-h) of ten selected GCMs of CMIP6, respectively

Fig. 3 Mean SSIS (top panel) and SSI (bottom panel) drought indices of China estimated from ten GCMs' simulations for two historical (1951-1980, 1985-2014) and two future (2041-2070, 20712100) periods under SSP2-4.5 (a-d for SSIS and i-l for SSI) and SSP5-8.5 climate scenarios (e-h for SSIS and m-p for SSI), respectively

Fig. 4 Mean SRIS (top panel) and SRI (bottom panel) drought indices estimated from ten GCMs' simulations for two historical (1951-1980, 1985-2014) and two future (2041-2070, 2071- 2100) periods under SSP2-4.5 (a-d for SRIS and i-l for SRI) and SSP5-8.5 climate scenarios (e-h for SRIS and m-p for SRI), respectively

Fig. 5 Mean scPDSI estimated from ten GCMs' simulations for two historical (1951-1980, 19852014) and two future (2041-2070, 2071-2100) periods under SSP2-4.5 (a-d) and SSP5-8.5 climate scenarios (e-h), respectively

Fig. 6 Mean SPEI estimated from ten GCMs' simulations for two historical (1951-1980, 19852014) and two future (2041-2070, 2071-2100) periods for SSP2-4.5 (a-d) and SSP5-8.5 scenarios (e-h), respectively

Fig. 7 Mean SPAEI estimated from ten GCMs' simulations for two historical (1951-1980, 19852014) and two future (2041-2070, 2071-2100) periods for SSP2-4.5 (a-d) and SSP5-8.5 scenarios (e-h), respectively

Fig. 8 Pearson correlation coefficients between SPEI and SPI, SPAEI and SPI, and scPDSI and SPI at 1- to 48-month time scales in the seven climatic regions of China under SSP2-4.5 and SSP5-8.5 scenarios, respectively

Fig. 9 Pearson correlation coefficients between SPEI and SSIS, SPAEI and SSIS, and scPDSI and SSIS at 1- to 48-month time scales in the seven climatic regions of China under SSP2-4.5 and SSP5- 
Fig. 10 Pearson correlation coefficients between SPEI and SRIS, SPAEI and SRIS, and scPDSI and SRIS at 1- to 48-month time scales in the seven climatic regions of China under SSP2-4.5 and SSP5-8.5 scenarios

Fig. 11 The percentage of drought areas estimated from scPDSI and SSIS of the seven climatic regions of China over the historical and future periods (1950-2100) projected under SSP2-4.5 and SSP5-8.5 climate scenarios of ten GCMs of CMIP6

Fig. 12 The severity of droughts estimated from scPDSI for the seven climatic regions of China over the historical and future periods (1950-2100) projected under SSP2-4.5 and SSP5-8.5 climate scenarios of ten GCMs of CMIP6

Fig. 13 The severity of droughts estimated from SSIS for the seven climatic regions of China over the historical and future periods (1950-2100) projected under SSP2-4.5 and SSP5-8.5 climate scenarios of ten GCMs of CMIP6 
Figures

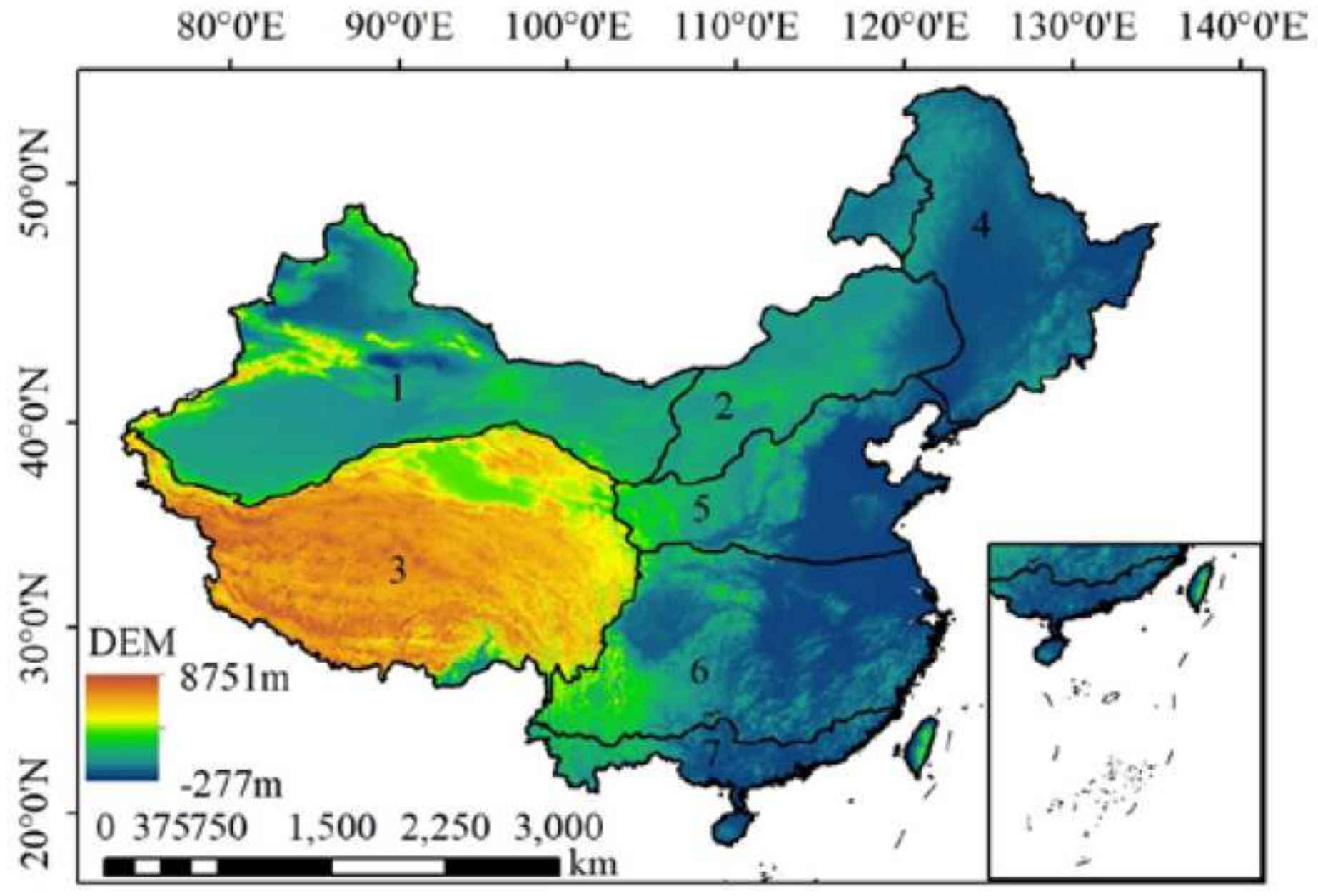

Figure 1

The digital elevation model (DEM) and seven climatic regions of China 

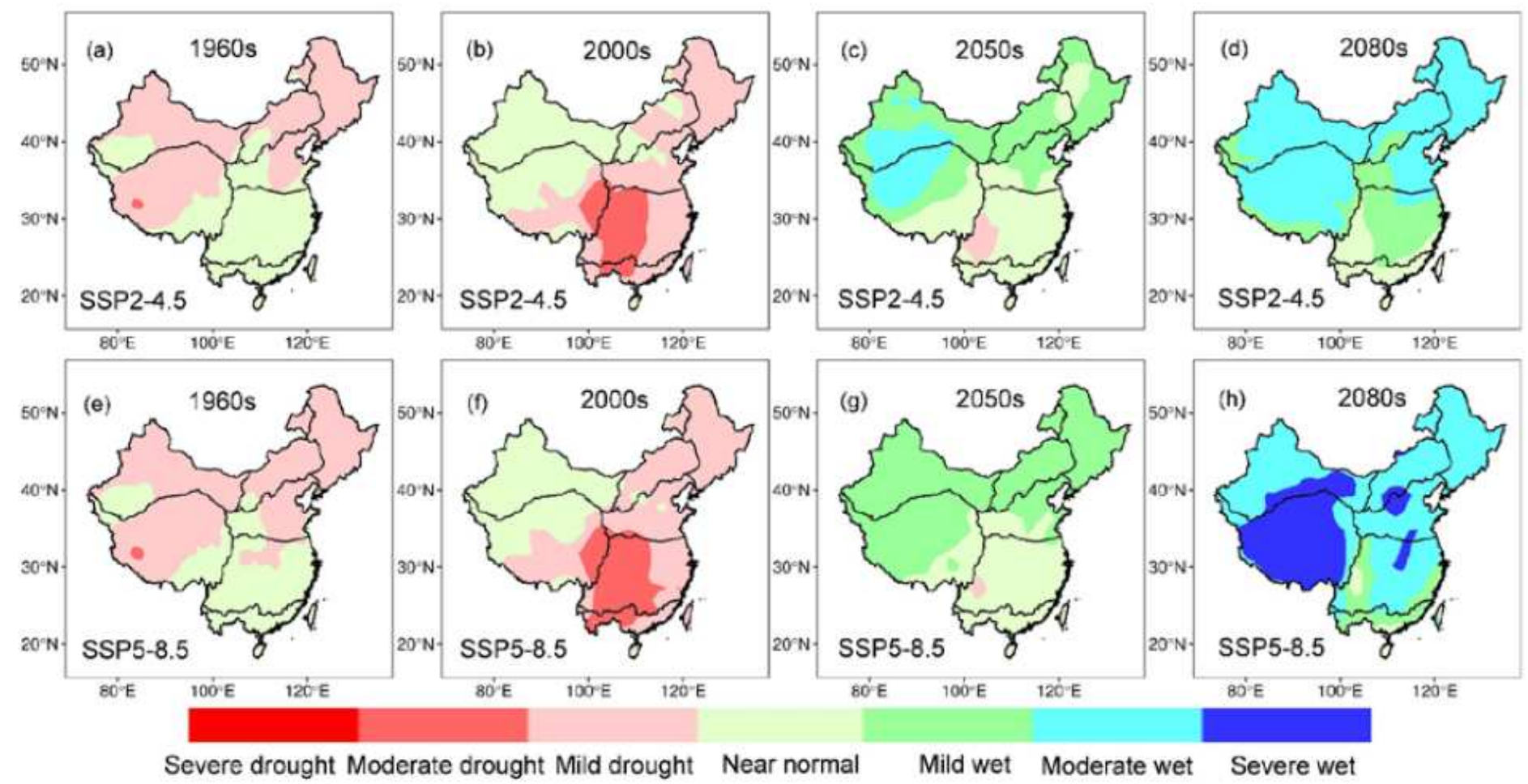

Figure 2

Averaged SPI estimated for China in two historical, 1951-1980 (1960s), 1985-2014 (2000s) and two future, 2041-2070 (2050s) and 2071-2100 (2080s), periods under SSP2-4.5 (a-d) and SSP5-8.5 climate scenarios (e-h) of ten selected GCMs of CMIP6, respectively 


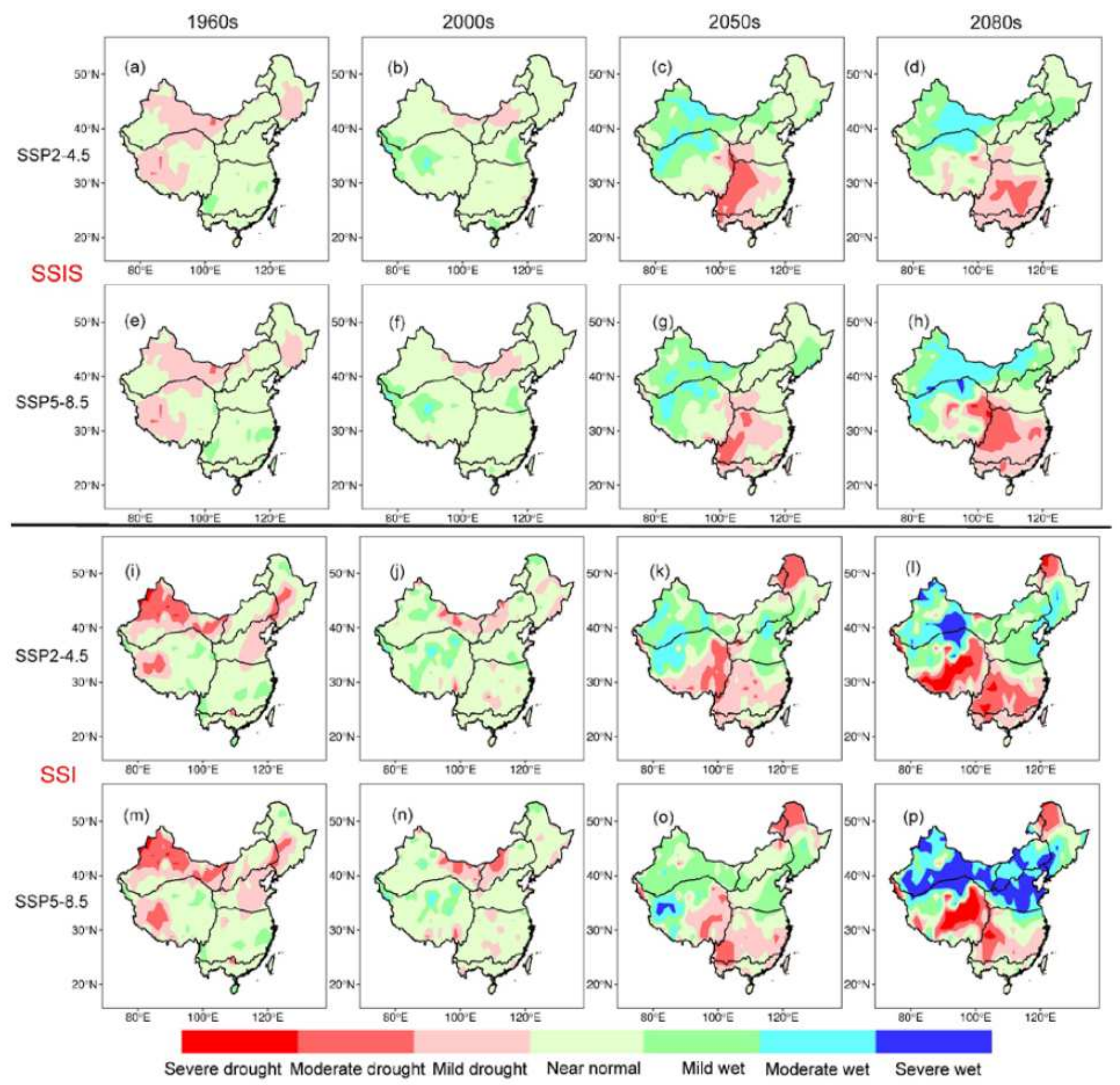

Figure 3

Mean SSIS (top panel) and SSI (bottom panel) drought indices of China estimated from ten GCMs' simulations for two historical (1951-1980, 1985-2014) and two future (2041-2070, 2071-2100) periods under SSP2-4.5 (a-d for SSIS and i-I for SSI) and SSP5-8.5 climate scenarios (e-h for SSIS and m-p for SSI), respectively 

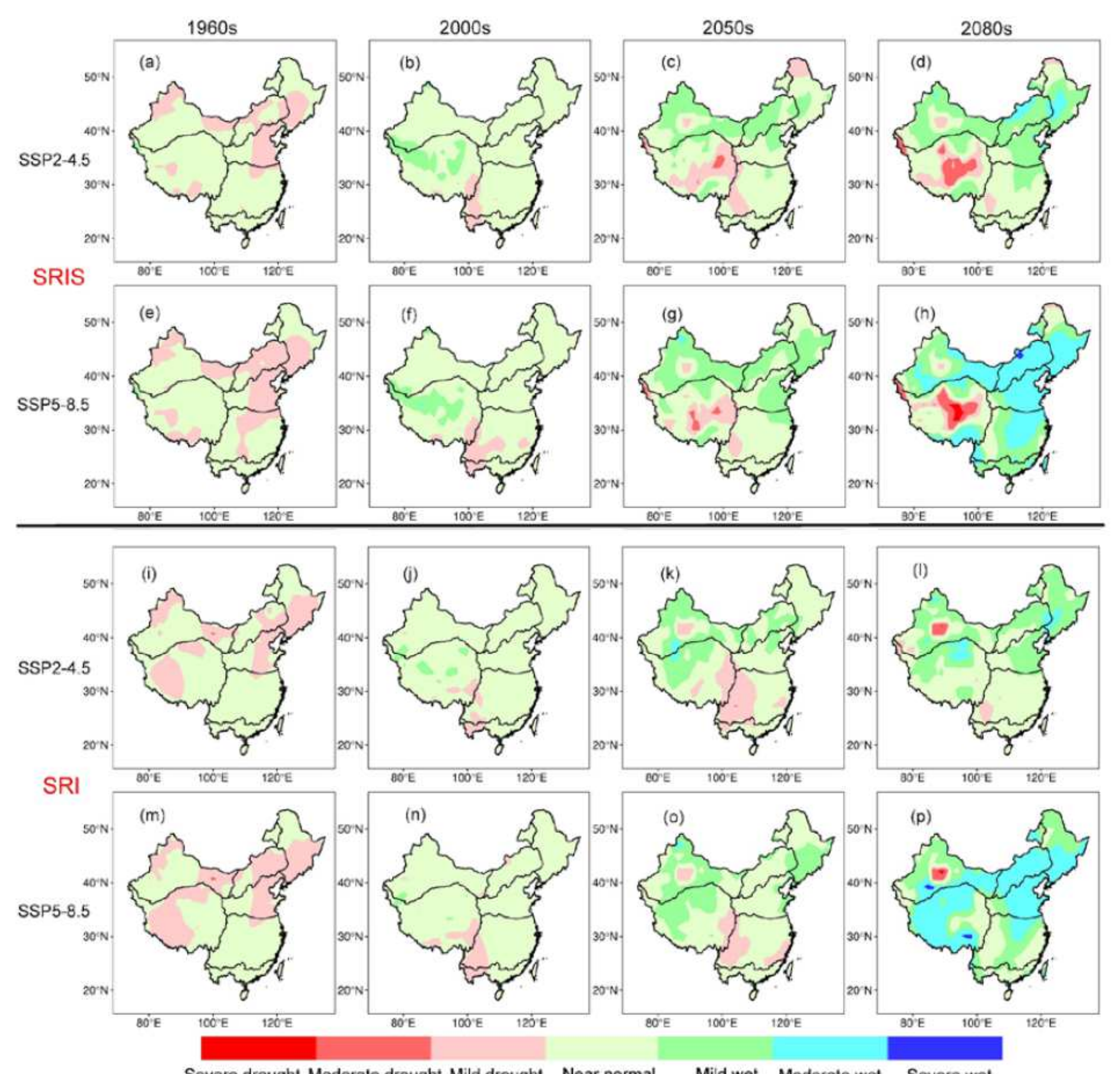

Severe drought Moderate drought Mild drought Near normal Mild wet Moderate wet Severe wet

\section{Figure 4}

Mean SRIS (top panel) and SRI (bottom panel) drought indices estimated from ten GCMs' simulations for two historical (1951-1980, 1985-2014) and two future (2041-2070, 2071- 2100) periods under SSP2-4.5 (a-d for SRIS and i-I for SRI) and SSP5-8.5 climate scenarios (e-h for SRIS and m-p for SRI), respectively 

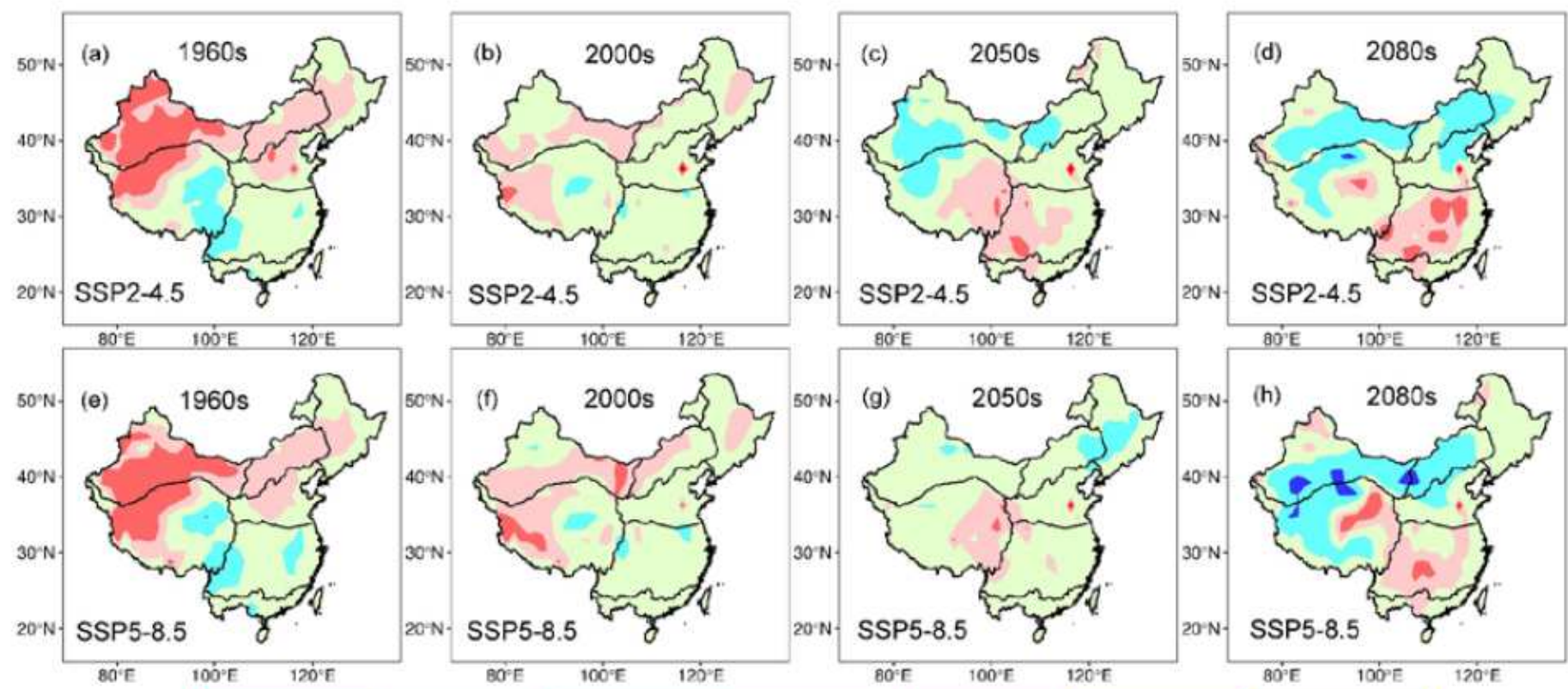

Severe drought Moderate drought Mild drought Near normal Mild wet Moderate wet Severe wet

\section{Figure 5}

Mean ScPDSI estimated from ten GCMs' simulations for two historical (1951-1980, 1985-2014) and two future (2041-2070, 2071-2100) periods under SSP2-4.5 (a-d) and SSP5-8.5 climate scenarios (e-h), respectively
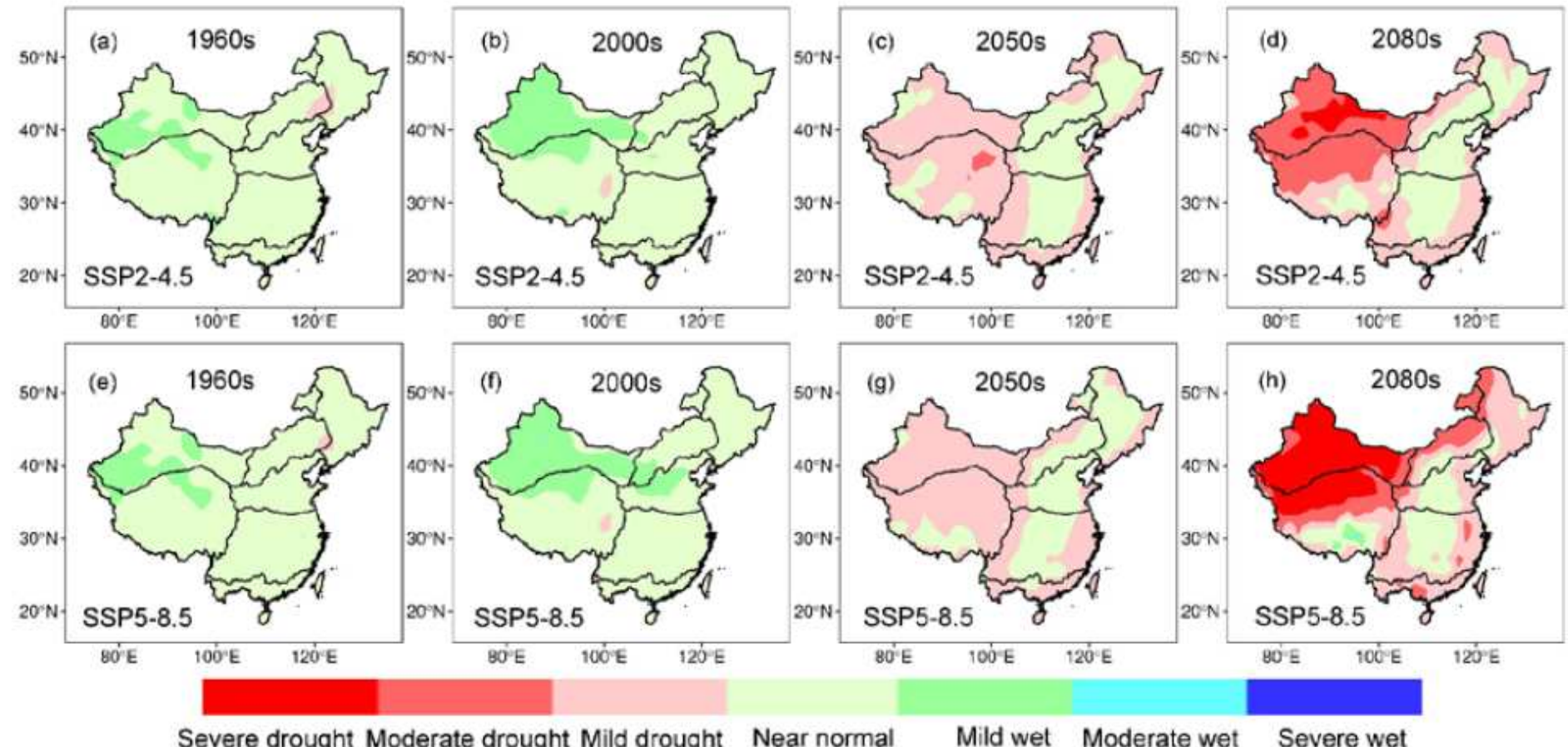

Severe drought Moderate drought Mild drought Near normal Mild wet Moderate wet Severe wet 
Mean SPEl estimated from ten GCMs' simulations for two historical (1951-1980, 1985-2014) and two future $(2041-2070,2071-2100)$ periods for SSP2-4.5 (a-d) and SSP5-8.5 scenarios (e-h), respectively

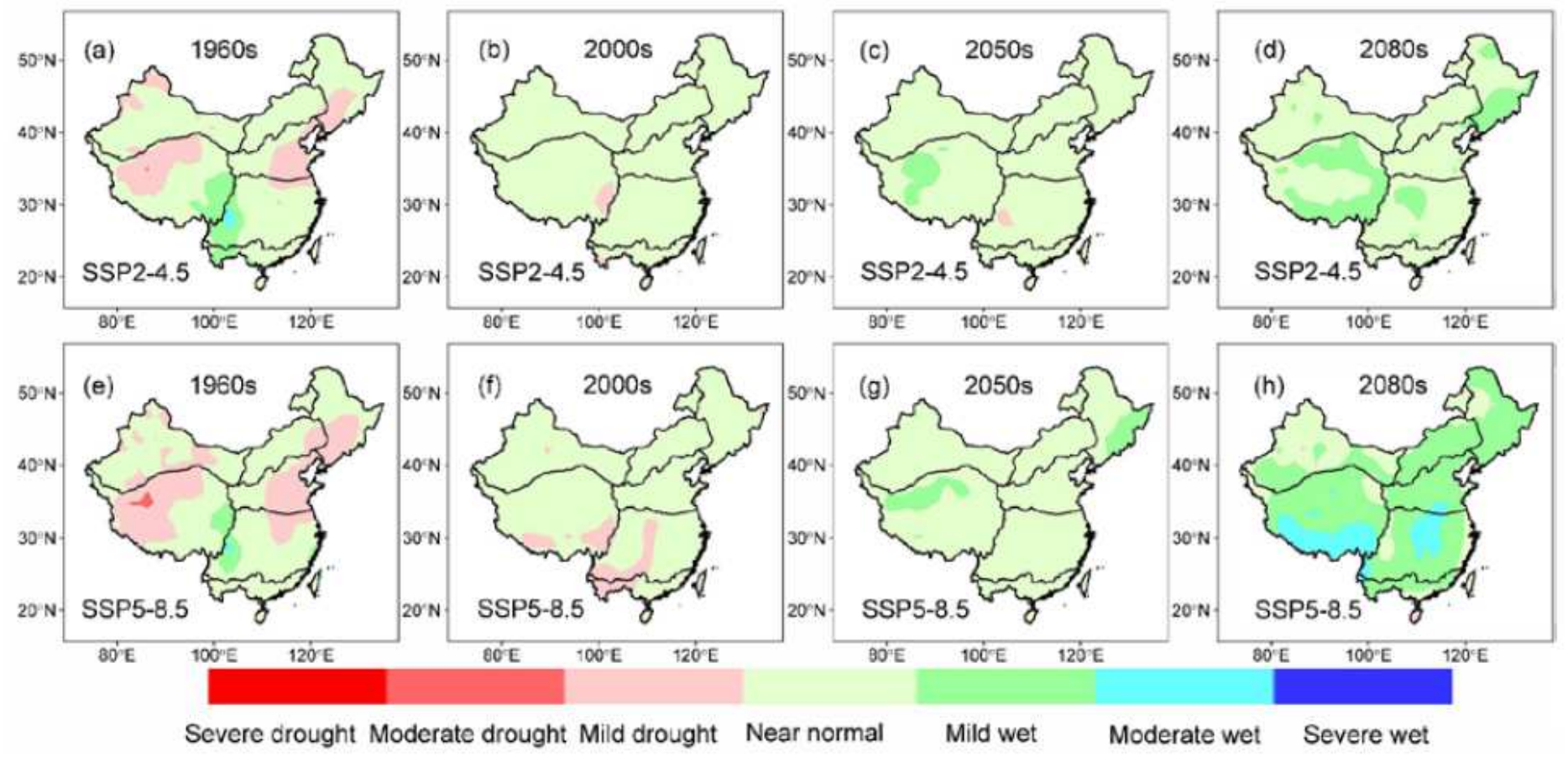

Figure 7

Mean SPAEl estimated from ten GCMs' simulations for two historical (1951-1980, 1985-2014) and two future (2041-2070, 2071-2100) periods for SSP2-4.5 (a-d) and SSP5-8.5 scenarios (e-h), respectively 

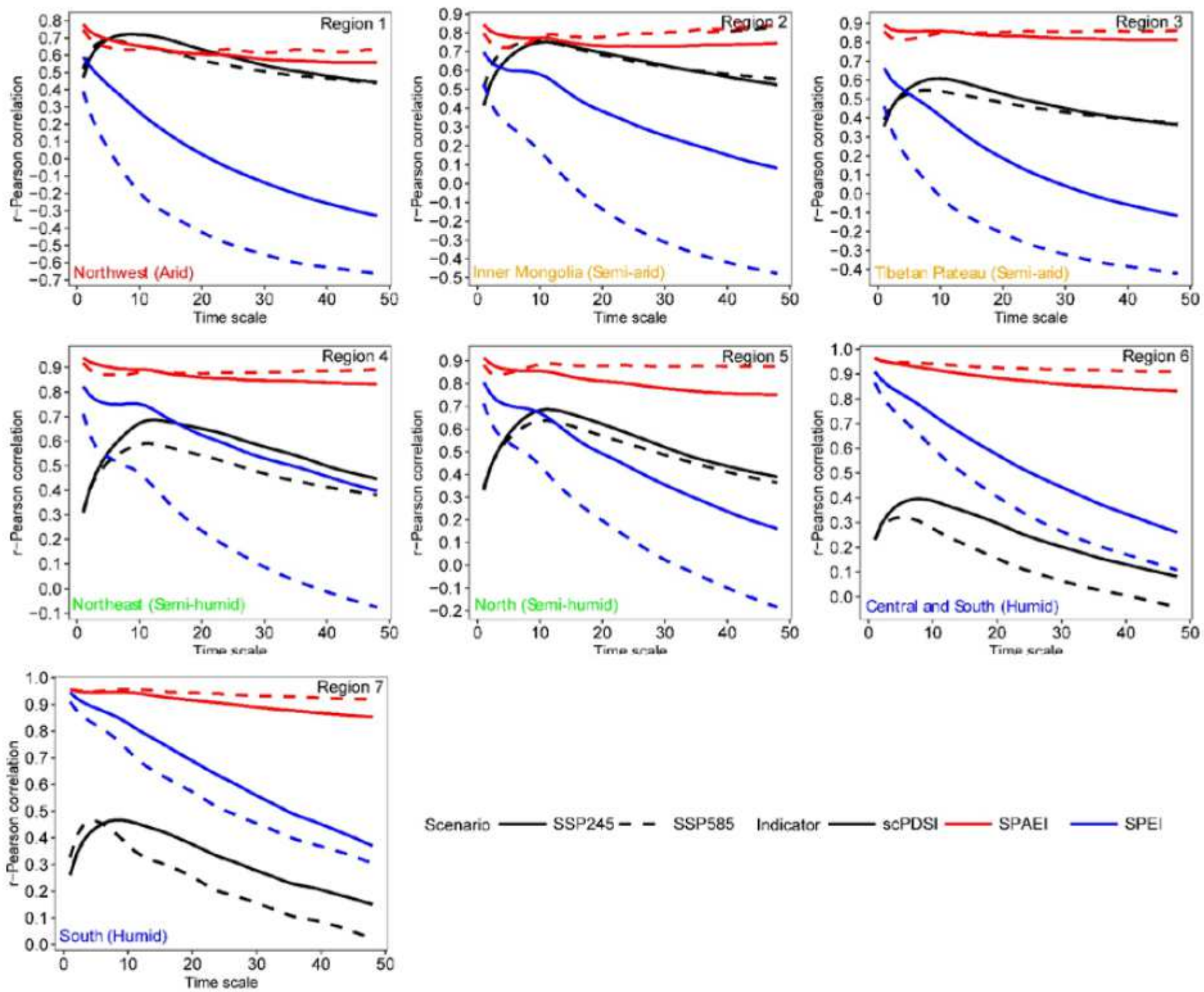

Scenario - SSP245 - - SSP585 Indicator — SCPOSI — SPAEI — SPEI

\section{Figure 8}

Pearson correlation coefficients between SPEI and SPI, SPAEI and SPI, and ScPDSI and SPI at 1- to 48month time scales in the seven climatic regions of China under SSP2-4.5 and SSP5-8.5 scenarios, respectively 

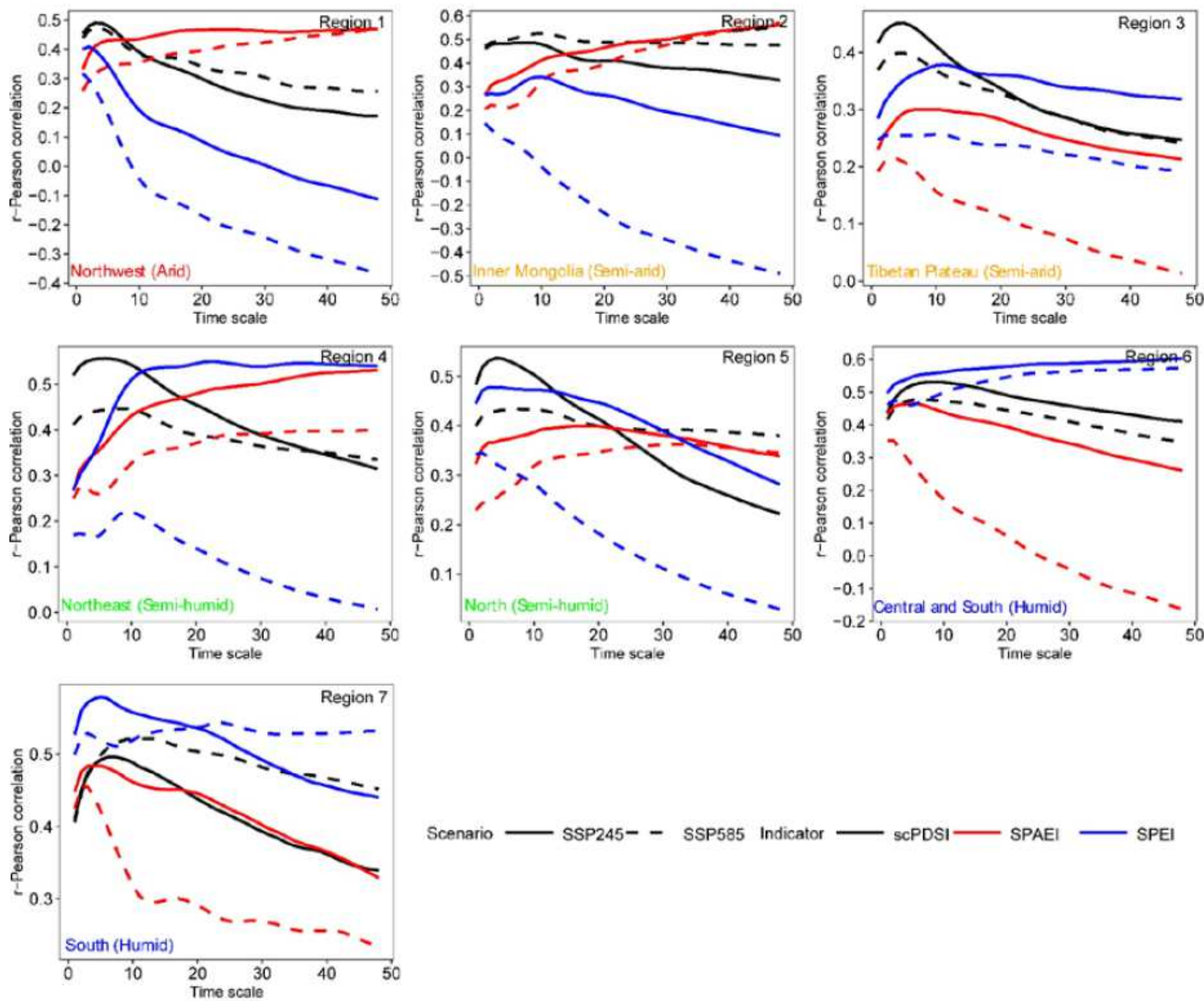

Scenario - SSP245- - SSP585 Indicator — SCPDSI- SPAEI — SPEI

\section{Figure 9}

Pearson correlation coefficients between SPEI and SSIS, SPAEI and SSIS, and SCPDSI and SSIS at 1- to 48-month time scales in the seven climatic regions of China under SSP2-4.5 and SSP5-8.5 scenarios, respectively 

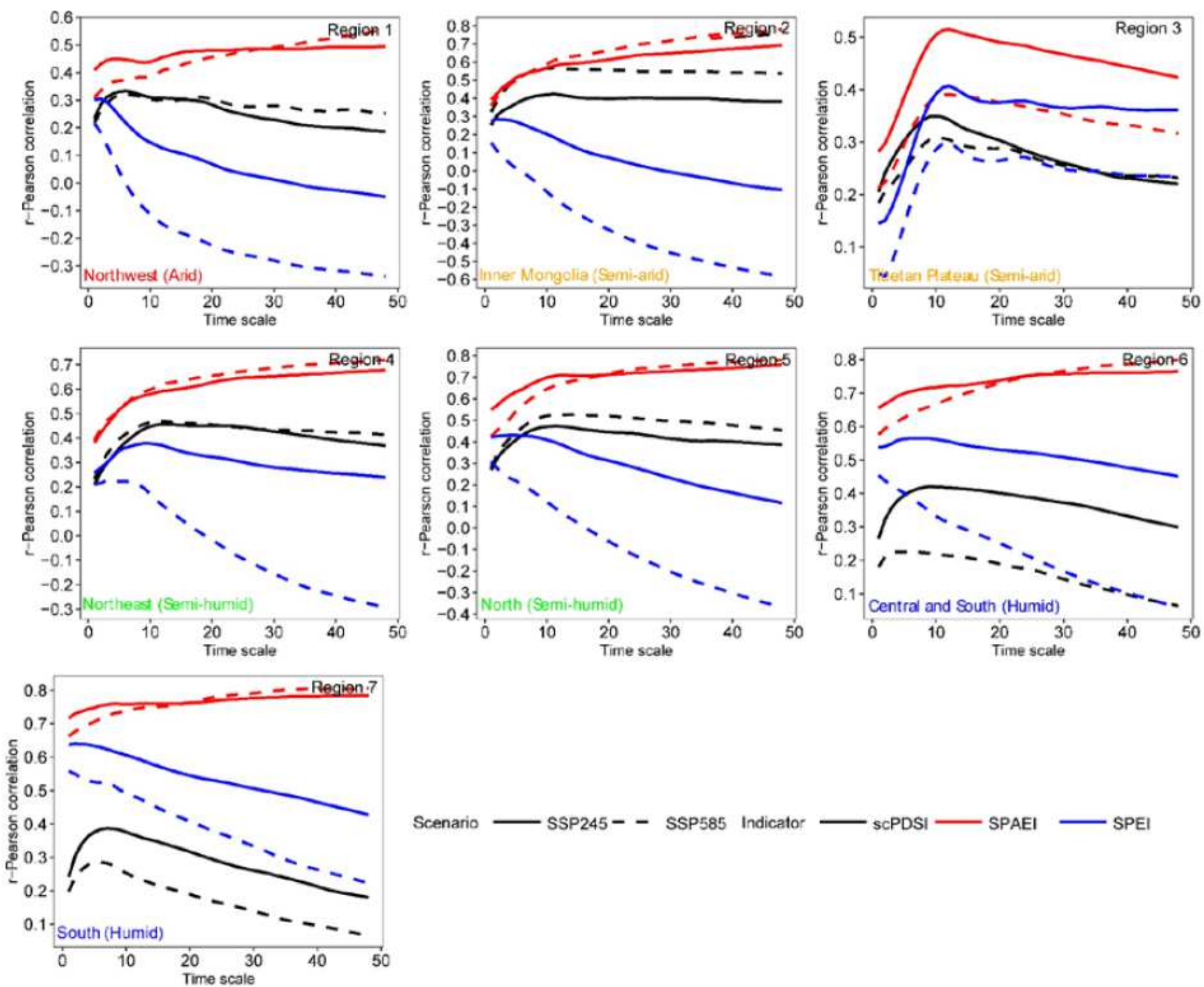

Scenario - SSP245- - SSP585 Indicator - SCPDSI - SPAEI - SPEI

\section{Figure 10}

Pearson correlation coefficients between SPEI and SRIS, SPAEI and SRIS, and SCPDSI and SRIS at 1- to 48-month time scales in the seven climatic regions of China under SSP2-4.5 and SSP5-8.5 scenarios 

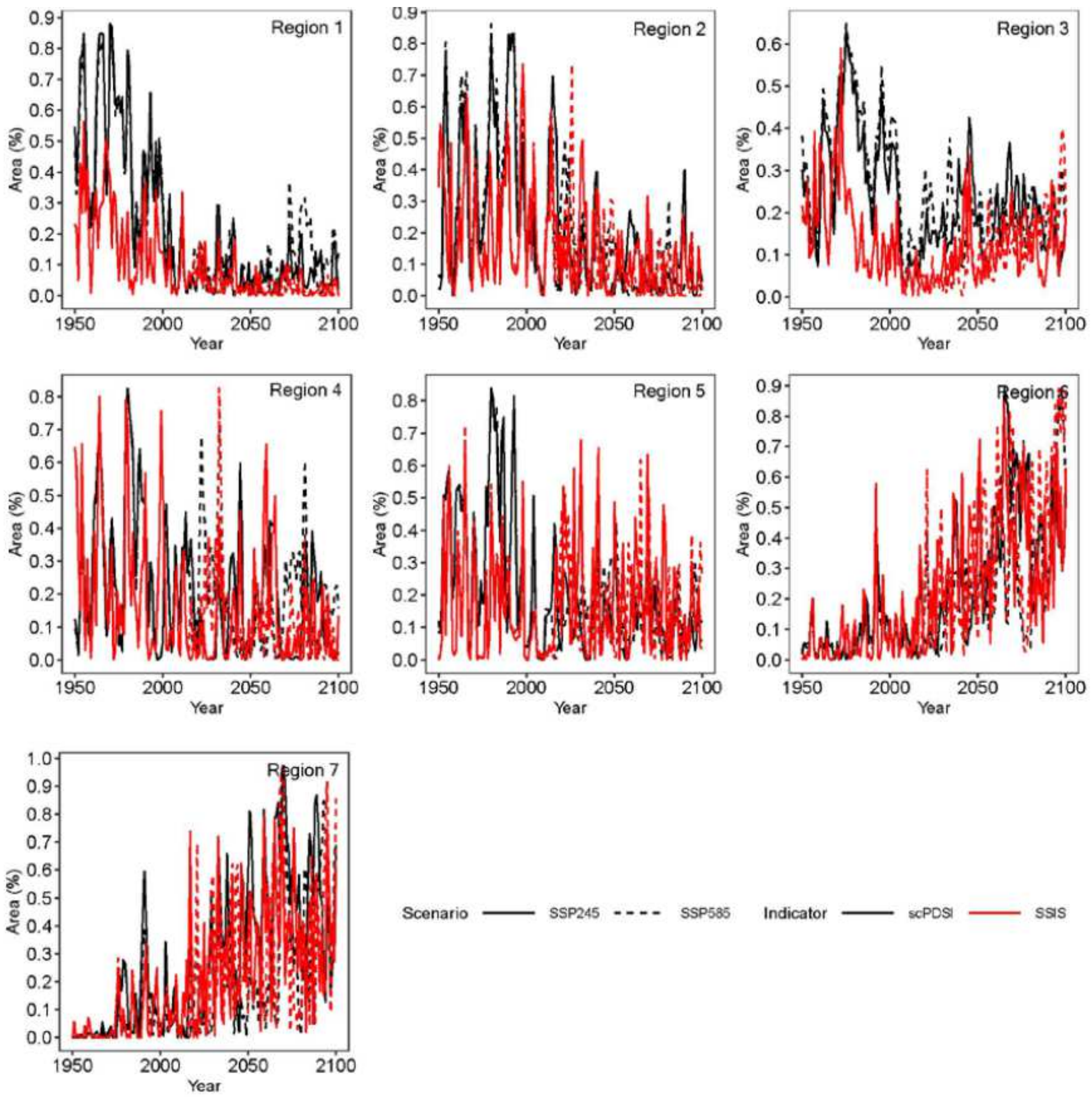

Scenario - SSP245 -..- SSP585 Indicator - ScPOSI- - SSS

Figure 11

The percentage of drought areas estimated from SCPDSI and SSIS of the seven climatic regions of China over the historical and future periods (1950-2100) projected under SSP2-4.5 and SSP5-8.5 climate scenarios of ten GCMs of CMIP6 

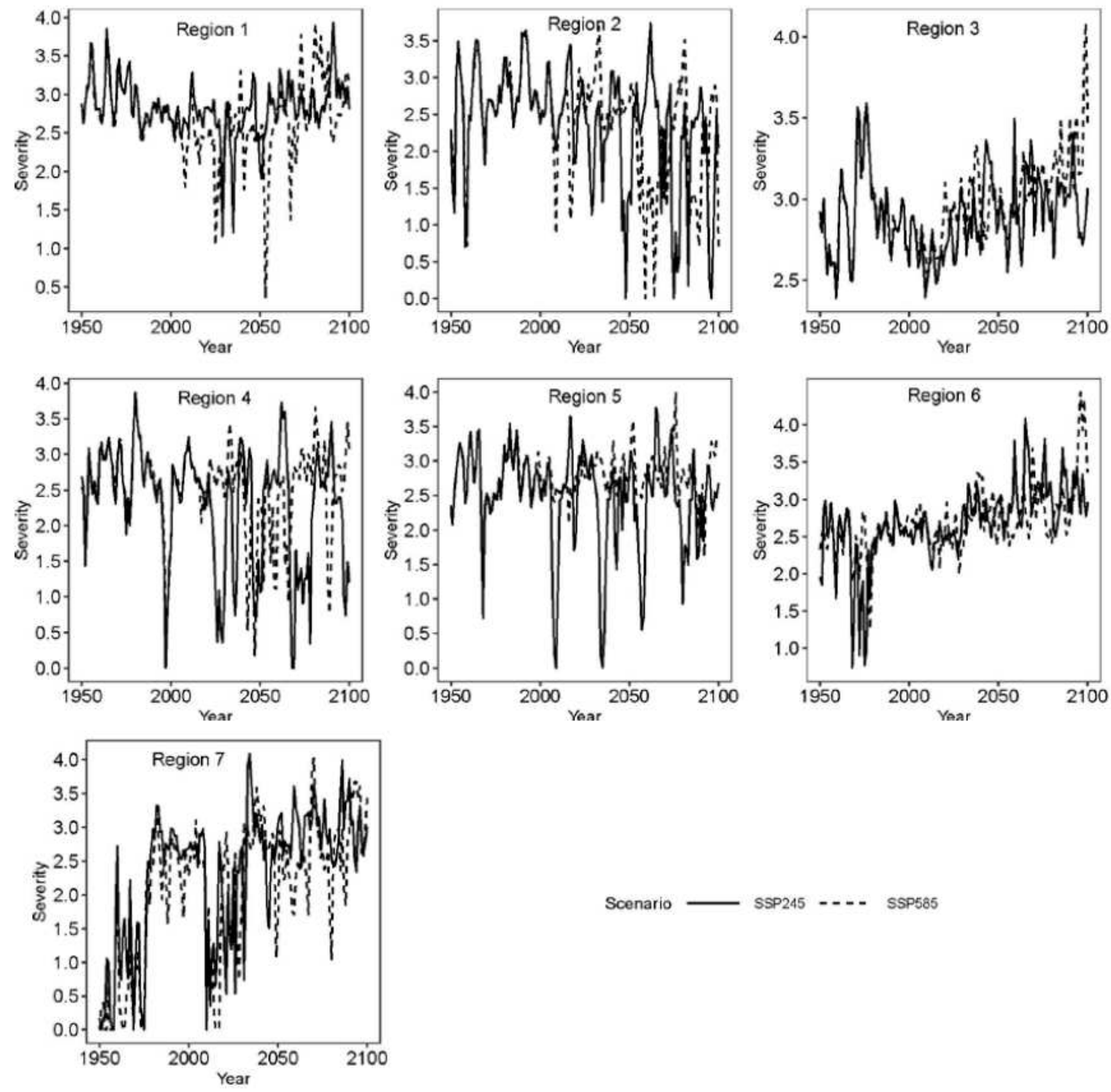

Figure 12

The severity of droughts estimated from ScPDSI for the seven climatic regions of China over the historical and future periods (1950-2100) projected under SSP2-4.5 and SSP5-8.5 climate scenarios of ten GCMs of CMIP6 

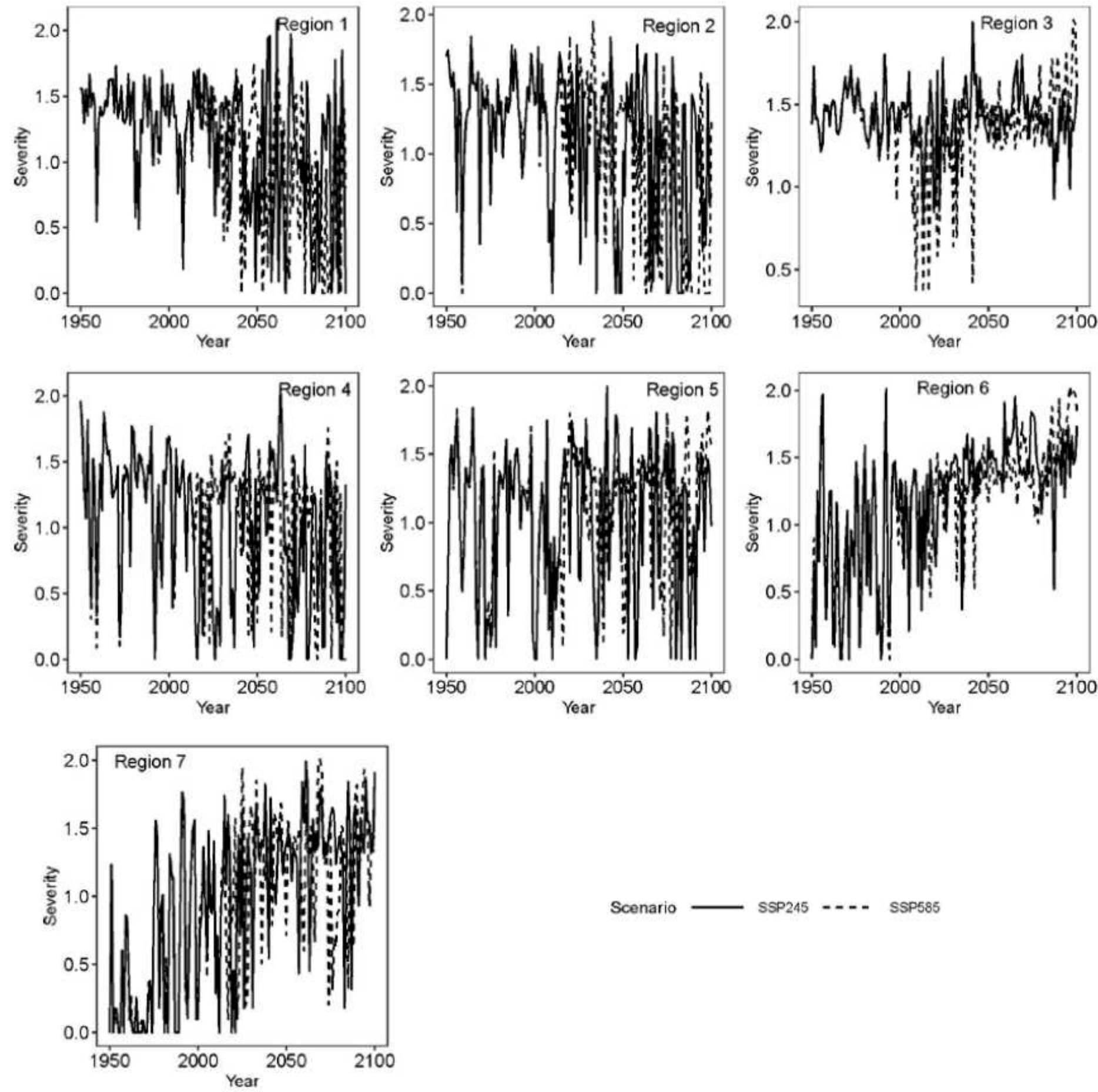

Figure 13

The severity of droughts estimated from SSIS for the seven climatic regions of China over the historical and future periods (1950-2100) projected under SSP2-4.5 and SSP5-8.5 climate scenarios of ten GCMs of CMIP6

\section{Supplementary Files}


This is a list of supplementary files associated with this preprint. Click to download.

- ESM1.pdf 